\title{
Old, Sick, Alone and Poor: A Welfare Analysis of Old-Age Social Insurance Programs *
}

\author{
R. Anton Braun \\ Karen A. Kopecky \\ Federal Reserve Bank of Atlanta \\ Federal Reserve Bank of Atlanta \\ r.anton.braun@atl.frb.org \\ karen.kopecky@atl.frb.org \\ Tatyana Koreshkova \\ Concordia University and CIREQ \\ tatyana.koreshkova@concordia.ca
}

May 2013

\begin{abstract}
Poor heath, large acute and long-term care medical expenses and spousal death are significant drivers of impoverishment among retirees. We document these facts and build a rich overlapping generations model that reproduces them. We use the model to assess the incentive and welfare effects of U.S. Social Security and means-tested social insurance programs, such as Medicaid and food stamp programs, for the aged. We find that U.S. means-tested social insurance programs for retirees provide significant welfare benefits for all newborn. Moreover, when means-tested social insurance benefits are of the scale in the U.S., all newborn prefer that Social Security be removed. Finally, we find that the current scale of means-tested social insurance in the U.S. is about right in the following sense. If we condition on the current Social Security program, the benefits of increasing means-tested social insurance are small or negative.
\end{abstract}

Keywords: Social Security; Medicaid; Social Insurance; Elderly; Medical Expenses.

JEL Classification numbers: E62, H31, H52, H55.

${ }^{*}$ We thank Mark Bils, Erich French, Victor Ríos and Gianluca Violante for their helpful comments and Neil Desai for excellent research assistance. We thank seminar participants at the Federal Reserve Bank of Atlanta. We are also grateful for comments from conference participants at the Wegman's Conference at the University of Rochester 2010, the 2012 Conference on Health and the Macroeconomy at the Laboratory for Aggregate Economics and Finance, UCSB, Fall 2012 Midwest Macroeconomics Meetings, 2013 MRRC Workshop, 2013 QSPS Summer Workshop, 2013 CIGS Conference on Macroeconomic Theory and Policy and the 2013 SED Meetings. 


\section{Introduction}

All individuals face some risk of ending up old, sick, alone and poor. Those who find themselves in this situation are often unable to work their way out of poverty by re-entering the labor force. In the U.S. two types of social insurance (SI) help retirees cope with this outcome: Social Security (SS) and means-tested SI such as Medicaid, Supplemental Social Security Income, food stamps, housing and energy assistance programs.

Milton Friedman in Cohen and Friedman (1972) argued that there is no need for SS and that a means-tested SI program is an efficient way to help retirees cope with this outcome. Feldstein (1987) showed that SS can be better than means-tested SI and went on to suggest that there may be a welfare enhancing role for having both programs when individuals are heterogenous.

Our objective is to consider the welfare and incentive effects of SS and means-tested SI programs in a model that explicitly recognizes the possibility that retirees may end up being old, sick, alone and poor. Consistent with Friedman, we find that there is no welfare enhancing role for SS when means-tested SI benefits are of the scale in the U.S. This result occurs in spite of the fact that removing SS has the large, negative incentive effects on savings of poorer households emphasized by Feldstein. This is not to say that there is no need for public SI for the aged. We find that means-tested SI has an important welfare enhancing role for retirees and that its current scale in the U.S. is about right. Modeling medical and long-term care expenses plays an essential role in these results.

A large macroeconomics literature has analyzed the role of SS in settings where there is only survival and/or lifetime earnings risk. A robust conclusion from this literature is that a pay-as-you-go SS program is bad public policy. This result has been documented

in models with dynastic households as in Fuster, Imrohoroğlu and Imrohoroğlu (2007) and also in a broad range of life cycle OLG models starting with the research of Auerbach and Kotlikoff (1987). İmrohoroğlu, İmrohoroğlu and Joines (1999) show that this result holds in dynamically efficient economies. Conesa and Krueger (1998) find that this result holds when agents face life-time earnings risk. Ríos and Hong (2007) show that this result holds when the economy is open and the pre-tax real interest rate is fixed. They also show that the result does not depend on the availability of private market substitutes such as private annuities and private life insurance. One exception to this general finding is Nishiyama and Smetters (2007) who show that the transition costs of privatizing SS may exceed the long-term benefits associated with a smaller SS program when labor market risk is uninsured.

A second and smaller strand of the literature has analyzed the efficacy of means-tested 
SI for retirees who are subject to permanent-earnings and survival risk. ${ }^{1}$ The idea that a means-tested SI program is more efficient than a universal SS program dates back to a debate by Wilbur Cohen and Milton Friedman. Friedman argued that the negative incentive effects of universal SS were so large that welfare would be improved if SS was replaced with a meanstested SI program (see Cohen and Friedman, 1972). In subsequent work, Feldstein (1987) has argued that means-tested SI for retirees has a particularly strong, negative incentive effect on some individuals. When means-tested SI is available and sufficiently liberal, these individuals will choose to consume all of their income when young and to rely on means-tested SI when they retire.

Tran and Woodland (2012) perform a quantitative general equilibrium analysis of Australia's public pension system. Australia is interesting because all public pensions are meanstested. They compare Australia's current system with an alternative economy with no means-tested public pension and find that agents prefer to be born into the latter economy. In their model the negative incentive effects emphasized by Feldstein (1987) are so strong that they dominate the positive insurance effects of means-tested SI. However, means-tested public pensions can be welfare improving if means-tested benefits are tapered off in a suitable way.

Perhaps the most relevant analysis to our question is conducted by Sefton, van de Ven and Weale (2008) who compare a universal SS system with the UK means-tested programs: the Minimum Income Guarantee program was in place prior to 2003 and narrowly targeted the poor; and the post-2003 UK public pension plan which lowered the effective tax rate on benefits from 100 to $40 \%$ of private income. They find in favor of Friedman. Young individuals prefer either form of means-tested public pension system over a universal SS system when factor prices are allowed to adjust and the fiscal budget is balanced.

This previous literature focuses exclusively on survival and permanent earnings risks and abstracts, in all cases, from medical and long-term care expense risk. İmrohoroğlu, İmrohoroğlu and Joines (1995) do model catastrophic health risk and find that modeling medical expenses does not have a large effect on savings and the welfare implications of SS reform. Their calibration of medical expenses is based on estimates by Feenberg and Skinner (1991). French and Jones (2004) have shown that Feenberg and Skinner (1991) underestimate the extent of medical expense risk faced by the elderly. DeNardi, French and Jones (2010) estimate a structural model of medical expenses faced by retirees and find that these expenses influence savings decisions of both rich and poor retirees. Kopecky and Koreshkova (2007) show that old-age, long-term care expenses and their risk have a

\footnotetext{
${ }^{1}$ Means-tested support for working individuals has received more attention in the literature, see e.g. Hubbard, Skinner and Zeldes (1995).
} 
significant effect on aggregate savings.

Medical and long-term care expenses are important risk factors for retirees because they increase with age and are concentrated in the final periods of life. These expenses are also correlated with other life events. For instance, a spousal death event that is preceded by large nursing home or hospital expenses can impoverish the survivor. We start by providing new evidence that widowhood, poor health, and hospital and nursing home stays are all associated with higher transitions into poverty. We then model these old age risks in a general equilibrium, life-cycle model of the U.S. economy.

Individuals enter the economy with a given level of educational attainment and a spouse and stay married throughout their working life. Labor productivity of working-age households evolves stochastically over the life-cycle and a borrowing constraint limits their ability to self-insure. Men's labor is supplied to the market inelastically, while female's labor supply is optimally chosen by the household. At age 65, all individuals retire.

Retired individuals in our model are subject to survival risk, health and out-of-pocket (OOP) medical expense risk, including the risk of a lengthy nursing home stay, and spousal death risk. These risks vary with age, gender and marital status of the retiree and are correlated with the retiree's education type. Thus retired households are heterogeneous not only in the size of their accumulated wealth (private savings and pensions), but also in the life expectancies of their members, household OOP medical expenses and household composition. We assume that there are no markets to insure against productivity, health, or survival risk. Partial insurance, however, is available to retirees through two programs run by the government: a progressive pay-as-you-go SS program that includes spousal and survivor benefits, and a means-tested SI program that guarantees a minimum consumption level to retirees.

We calibrate the model to match a set of aggregate and distributional moments for the U.S. economy, including demographics, earnings, medical and nursing home expenses, as well as features of the U.S. means-tested social welfare, SS and income tax systems. We then assess the model's ability to reproduce key facts observed in the data but not targeted in the calibration. In particular, we show that the model generates patterns consistent with the data with regards to Medicaid take-up rates, flows into Medicaid and OOP medical expenses by age and marital status. Moreover, we show that the model delivers an increased likelihood of impoverishment for individuals who experience: large acute and long-term care OOP expenses; shocks to health status; or a spousal death event. These patterns of impoverishment in the model are in line with impoverishment statistics in our dataset obtained from the Health and Retirement Survey (HRS).

To assess Friedman's claim that means-tested SI is an efficient way to insure retirees 
against old-age risks, we start by comparing economies with only SS or only means-tested SI, of the scale of these programs in the U.S., with an economy with no SI. Introducing SS into an economy with no SI programs reduces average welfare by $5.11 \%$ of lifetime consumption. This occurs because the return on SS contributions is much lower than the effective real return on private savings. ${ }^{2}$

We consider next compare the economy with no SI with an economy with means-tested SI only. Consistent with Feldstein's arguments we find that introducing means-tested SI has a significant negative incentive effect on the poor and many chose not to save at all for retirement. Twenty-one percent of individuals roll into means-tested SI immediately upon retiring. However, these negative incentive effects are dominated by a positive insurance effect and average welfare of a newborn increases by $14 \%$. This large positive insurance effect stems from the fact that means-tested SI transfers pay out in situations where medical expenses are large and thus the need for insurance is greatest. SS benefits do not have this state-contingent feature and are therefore a less effective form of insurance against old-age medical risks.

Even though we find that SS only is not welfare improving, it could be that there is a welfare enhancing role of having both means-tested SI and SS due to interactions between the two programs. To ascertain the answer we consider the introduction of SS into the economy with means-tested SI only. Introducing SS lifts a large fraction of retirees out of poverty. Means-tested take-up rates of retirees decline from $34 \%$ to $13 \%$ and government outlays on this program fall from $2.52 \%$ to $0.80 \%$ of GNP. The reason why introducing SS has such a dramatic impact on means-tested SI take-up rates is because it ameliorates the negative saving effect of means-tested SI. SS 'forces' some households, who would choose not to save otherwise, to save for retirement. This forced savings increases the effective expected return from saving and some households alter their strategy and choose to save on their own as well. This fiscal benefit of introducing SS is not welfare improving: welfare of all types of newborn falls. Affluent households like this fiscal benefit but the poor do not. Effectively forcing the poor to save lowers their utility. These factors in conjunction with the low effective return of SS contributions act to lower average welfare of newborn by $11.8 \%$. Thus we find that even though the negative incentive effects emphasized by Feldstein are large, Friedman's suggestion that SS be removed enhances welfare in the long-run.

Our results suggest that there may be a role for increasing the scale of means-tested SI in the U.S. To explore this possibility, we condition on the current SS program and consider

\footnotetext{
${ }^{2}$ This cost of SS is well known and is most pronounced when the real interest rate is held fixed. It stems from the fact that the effective return on SS contributions is given by the growth rate of aggregate labor income which is lower than the effective real return on capital in a dynamically efficient economy.
} 
two strategies for financing a 30 percent increase in means-tested SI benefits for retirees. When the increase is financed by a payroll tax, welfare increases by $0.54 \%$ of consumption. However, when the increase is financed by income taxes, welfare falls instead by $-0.44 \%$.

Medical and long-term care expenses play a central role in our findings. When medical expenses are set to zero, households prefer an economy with no SI instead of our representation of the U.S. economy with both SI programs. Medical expense risks also matter for the size of the disincentive effects emphasized by Feldstein (1987). These negative incentive effects become very small when medical expenses are zero. Finally, medical expense risks affect the welfare benefits of means-tested SI. The benefits provided by this program are much more valuable to households when medical expense risks are present.

The remainder of the paper is organized as follows. In Section 2, we motivate our analysis by providing evidence on sources of impoverishment for the elderly. Section 3 describes the model. Section 4 reports how we estimate and calibrate the various parameters and profiles that are needed to solve the model. In Section 5, we assess the ability of the model to reproduce statistics not targeted in the calibration, including flows into Medicaid by age and martial status, as well as a variety of wealth mobility statistics for retirees. Section 6 reports results from our welfare analysis. Finally, Section 7 contains our concluding remarks.

\section{Motivation}

In this section we provide some new empirical evidence that illustrates that shocks that occur during retirement are important sources of impoverishment for retirees. In particular, we show that longevity, widowhood, poor health, and large acute and long-term care medical expenses are all associated with transitions into impoverishment during retirement.

Before discussing impoverishment it is useful to first document some basic facts about wealth mobility for retired individuals. Table 1 reports wealth transition statistics by age and wealth quintile using data from the HRS. Our measure of wealth is total wealth excluding the primary residence. The data frequency is two years and the table reports pooled two-year transitions for individuals grouped into three age brackets 65-74, 75-84 and 85+. Table 1 has several noteworthy features. Observe first that persistence of wealth, as measured by the percentage of individuals who report no-change, decreases with age. While the decrease is less pronounced going from the 65-74 year-olds to the 75-84 year-olds, there is a strong decline in persistence going to the 85 and older group. The decline in persistence occurs in all five wealth quintiles. Second, observe that there is evidence of mean reversion in the wealth distribution. The percentage of those moving up in the wealth distribution conditional on

being in quintiles $1-2$ is larger than the percentage of those moving down. In quintiles 
Table 1: Two-year wealth mobility of retired individuals age 65 and over

\begin{tabular}{c||ccc|ccc|ccc}
\hline \hline \multirow{2}{*}{ Quintile } & \multicolumn{2}{c|}{$65-74$ Year-olds } & \multicolumn{2}{c|}{$75-84$ Year-olds } & \multicolumn{3}{c}{$85+$ Year-olds } \\
down & up & stay & down & up & stay & down & up & stay \\
\hline 1 & 0.0 & 27.6 & 72.4 & 0.0 & 26.4 & 73.6 & 0.0 & 43.7 & 56.3 \\
2 & 22.6 & 22.6 & 54.8 & 20.8 & 24.6 & 53.6 & 30.2 & 26.0 & 43.7 \\
3 & 22.2 & 21.1 & 56.7 & 21.8 & 23.6 & 54.6 & 24.3 & 27.1 & 48.7 \\
4 & 21.5 & 15.9 & 62.6 & 24.8 & 17.0 & 58.2 & 27.8 & 18.2 & 54.0 \\
5 & 18.7 & 0.0 & 81.3 & 22.0 & 0.0 & 78.0 & 22.3 & 0.0 & 77.7 \\
\hline \hline
\end{tabular}

The percentage of retired individuals, aged $65+$, moving down, moving up and staying in the same quintile of the wealth distribution over a 2-year period. Authors' computations. Data: 1995-2010 HRS/AHEAD retired individuals aged $65+$. See 8.1.1 for more details.

4 and 5 the story is reversed with a larger percentage of moves down. The third wealth quintile is rather interesting because for this quintile we see a higher percentage of moves up as compared to moves down for the older age-groups. We will document below that as retirees age an increasing fraction of them rely on means-tested welfare support. Given this observation it appears that the left tail of the wealth distribution is getting fatter as individuals age.

How does wealth mobility among retirees vary by marital status? Table 2 reports probabilities of two year transitions from the five wealth quintiles to quintile 1 for married females and for widows. A higher percentage of widows experience impoverishment as compared to married women. In particular, a higher percentage of widows transit to quintile 1 from every other wealth quintile as compared to married women. This pattern is robust across wealth quintiles and also across age with one exception. For $85+$ year old women in the second wealth quintile the percentage experiencing transitions to quintile 1 is about the same for married women and widows.

Poverty is also more persistent for widows than married women aged 65-74 and 7584. ${ }^{3}$ The percentage of quintile 1 to quintile 1 transitions for married women and widows is respectively $73 \%$ and $80 \%$ for women aged $65-74$ and $70 \%$ for married versus $76 \%$ for widows in the 75-84 age group.

Table 3 reports the same comparisons for married and single men. Similar patterns are evident here and, if anything, the findings are even more consistent for widowers. A higher percentage of widowers experience two year transitions to impoverishment as compared to married men and poverty is a more persistent state for widowers.

\footnotetext{
${ }^{3}$ Throughout this paper we will use the term "poverty" to refer to those in quintile 1 . These are the poorest people in our economy in a relative sense.
} 
Table 2: Percentage of retired women moving from each quintile of the wealth distribution to quintile 1 two years later by marital status

\begin{tabular}{c||cc|cc|cc}
\hline \hline \multirow{2}{*}{} & \multicolumn{2}{c||}{$65-74$ Year-olds } & \multicolumn{2}{c|}{$75-84$ Year-olds } & \multicolumn{2}{c}{$85+$ Year-olds } \\
Quintile & Married & Widowed & Married & Widowed & Married & Widowed \\
\hline 1 & 72.5 & 80.0 & 69.6 & 75.9 & 80.2 & 76.1 \\
2 & 17.3 & 22.9 & 17.2 & 20.6 & 28.1 & 28.0 \\
3 & 3.4 & 6.5 & 4.4 & 6.9 & 8.1 & 11.5 \\
4 & 1.0 & 1.6 & 1.1 & 2.4 & 3.7 & 6.2 \\
5 & 0.4 & 1.1 & 0.3 & 0.5 & 2.6 & 2.8 \\
\hline \hline
\end{tabular}

The percentage of women moving down to quintile 1 from quintiles 2-5 in a 2-year period by marital status in the initial period. The first row is the percentage of women who stay in quintile 1. Authors' computations. Data: 1995-2010 HRS/AHEAD retired women aged 65+. See 8.1.1 for more details.

Table 3: Percentage of retired men moving from each quintile of the wealth distribution to quintile 1 two years later by marital status

\begin{tabular}{c||cc|cc|cc}
\hline \hline \multirow{2}{*}{\multicolumn{1}{c||}{}} & \multicolumn{2}{c|}{$65-74$ Year-olds } & \multicolumn{2}{c|}{$75-84$ Year-olds } & \multicolumn{2}{c}{$85+$ Year-olds } \\
Quintile & Married & Widowed & Married & Widowed & Married & Widowed \\
\hline 1 & 74.5 & 75.7 & 73.9 & 79.0 & 70.7 & 73.9 \\
2 & 18.3 & 24.1 & 17.4 & 18.8 & 15.0 & 19.2 \\
3 & 3.9 & 12.2 & 3.5 & 9.6 & 4.6 & 8.1 \\
4 & 1.3 & 3.5 & 2.0 & 2.0 & 4.1 & 4.3 \\
5 & 0.7 & 1.7 & 0.9 & 1.8 & 0.0 & 4.0 \\
\hline \hline
\end{tabular}

The percentage of men moving down to quintile 1 from quintiles 2-5 in a 2-year period by marital status in the initial period. The first row is the percentage of men who stay in quintile 1. Authors' computations. Data: 1995-2010 HRS/AHEAD retired men aged 65+. See 8.1.1 for more details. 
Table 4: Percentage of retired individuals moving from each quintile of the wealth distribution to quintile 1 two years later by health status

\begin{tabular}{c||cc|cc|cc}
\hline \hline \multirow{2}{*}{ Quintile } & \multicolumn{2}{||}{$\begin{array}{c}65-74 \\
\text { Healthy }\end{array}$} & Year-olds & \multicolumn{2}{c|}{$75-84$ Year-olds } & \multicolumn{2}{c}{$85+$ Year-olds } \\
Unhealthy & Healthy & Unhealthy & Healthy & Unhealthy \\
\hline 1 & 69.7 & 80.9 & 70.8 & 79.3 & 67.8 & 73.1 \\
2 & 15.6 & 22.6 & 15.1 & 22.1 & 17.7 & 27.5 \\
3 & 3.4 & 5.5 & 3.8 & 7.2 & 7.8 & 8.2 \\
4 & 0.9 & 2.2 & 1.3 & 4.1 & 4.1 & 4.7 \\
5 & 0.4 & 1.5 & 0.5 & 1.3 & 1.4 & 2.8 \\
\hline \hline
\end{tabular}

The percentage of individuals moving down to quintile 1 from quintiles $2-5$ in a 2 -year period by health status in the initial period. The first row is the percentage of individuals who stay in quintile 1. Authors' computations. Data: 1995-2010 HRS/AHEAD retired individuals aged 65+. See 8.1.1 for more details.

A second empirical regularity is that poor health is associated with higher flows into poverty. Table 4 shows that a self report of poor health is associated with a higher frequency of moves from quintiles 2-5 to quintile 1 two years later. ${ }^{4}$ Some of the differences are small, but we find it remarkable that the pattern is consistent across quintiles and all three age groups. A report of poor health is also associated with higher persistence of poverty. The difference is largest for the 65-74 age group and narrows a bit as individuals age.

Poor health is often associated with higher medical expenditures. Medical expenditures fall into two broad categories: acute (immediate and severe) expenses and long-term care expenses. In our HRS data the largest acute medical expenses are those associated with a hospital stay. Table 5 reports wealth mobility transitions to the first wealth quintile for individuals who experience a hospital stay and those who do not. Hospital stays are associated with an increased frequency of transitions to quintile 1 . The differences here are weaker compared to some of the previous indicators with two ties and one reversal. But the impoverishing effect of a hospital stay is clearly discernible in Table 5. Quintile 1 is also a more persistent state conditional on a hospital stay event for the two youngest age groups. Given that acute medical expenses are transient in nature, it is not surprising at all to see that the pattern of impoverishment is a bit weaker here as compared to e.g. self-reported health status.

Finally, consider long-term care. Nursing home expenses are the largest long-term care expense. The cost of a one-year stay in a nursing home can easily exceed $\$ 60,000$ and while the average duration is only approximately two years, Brown and Finkelstein (2008) estimate that approximately $9 \%$ of entrants will spend more than five years in a nursing

\footnotetext{
${ }^{4}$ See 8.1 for a description of our health variable.
} 
Table 5: Percentage of retired individuals moving from each quintile of the wealth distribution to quintile 1 two years later conditional on whether or not they stayed overnight in a hospital in the initial period

\begin{tabular}{c||cc|cc|cc}
\hline \hline \multirow{2}{*}{} & \multicolumn{2}{c|}{ 65-74 Year-olds } & \multicolumn{2}{c|}{$75-84$ Year-olds } & \multicolumn{2}{c}{$85+$ Year-olds } \\
Quintile & None & Hospital Stay & None & Hospital Stay & None & Hospital Stay \\
\hline 1 & 75.3 & 79.0 & 73.1 & 78.8 & 71.0 & 70.8 \\
2 & 18.1 & 18.9 & 16.9 & 18.2 & 20.9 & 22.9 \\
3 & 3.6 & 5.1 & 3.8 & 6.6 & 7.8 & 7.7 \\
4 & 0.9 & 1.6 & 1.7 & 2.5 & 4.0 & 4.3 \\
5 & 0.6 & 0.4 & 0.6 & 0.6 & 2.2 & 1.3 \\
\hline \hline
\end{tabular}

The percentage of individuals moving down to quintile 1 from quintiles $2-5$ in a 2 -year period conditional on an overnight hospital stay in the initial period. The first row is the percentage of individuals who stay in quintile 1. Authors' computations. Data: 1995-2010 HRS/AHEAD retired individuals aged 65+. See 8.1.1 for more details.

home. Table 6 reports wealth transitions for individuals who experience nursing-home-stay events and those who do not. The pattern here is very similar to the pattern for hospital stays. Given the cost of nursing home stays, it is not surprising to see that there are more pronounced differences between the two types of individuals when the event is a nursing home stay instead of a hospital stay.

The pattern of correlations that emerges in these transitions yields a surprisingly consistent picture. Impoverishment is positively associated with widowhood, poor health and both acute and long-term medical events. In particular, individuals who are widowed, in poor health or who experience one of these medical events have a higher likelihood of transiting into the first wealth quintile. All of these characteristics are also associated with a higher expected stay in the first quintile.

\section{The Model}

We consider the roles of social security and Medicaid in an overlapping generations model with two-member households that face earnings, health, medical expense and survival risk. Factor markets are competitive and there are no private insurance markets. Households' ability to self-insure is further limited by a no-borrowing constraint. 
Table 6: Percentage of retired individuals moving from each quintile of the wealth distribution to quintile 1 two years later conditional on whether or not they spent time in a nursing home $(\mathrm{NH})$ in the initial period

\begin{tabular}{c||cc|cc|cc}
\hline \hline \multirow{2}{*}{ Quintile } & \multicolumn{2}{||}{$65-74$ Year-olds } & \multicolumn{2}{c|}{$75-84$ Year-olds } & \multicolumn{2}{c}{$85+$ Year-olds } \\
None & NH Stay & None & NH Stay & None & NH Stay \\
\hline 1 & 75.7 & 87.9 & 74.6 & 86.0 & 69.3 & 75.6 \\
2 & 18.0 & 25.6 & 17.4 & 23.7 & 20.2 & 31.8 \\
3 & 3.8 & 9.6 & 4.5 & 11.8 & 7.1 & 14.3 \\
4 & 1.0 & 5.3 & 1.8 & 5.0 & 3.5 & 8.2 \\
5 & 0.5 & 3.3 & 0.5 & 3.9 & 1.5 & 4.6 \\
\hline \hline
\end{tabular}

The percentage of individuals moving down to quintile 1 from quintiles $2-5$ in a 2 year period conditional on a nursing home stay in the initial period. The first row is the percentage of individuals who stay in quintile 1. Authors' computations. Data: 1995-2010 HRS/AHEAD retired individuals aged 65+. See 8.1.1 for more details.

\subsection{Demographics}

Time is discrete. The economy is populated by overlapping generations of households. Population grows at a constant rate $n$. Newborns are assigned to two-member households at age 1. Each member is endowed with a gender and an education type. We use $x_{s}^{i}$ to denote the fraction of individuals of gender $i \in\{m, f\}$ with either high school or college educational attainment $s \in\{h s, c o l\}$. The distribution of households across education types $\mathbf{s} \equiv\left(s^{m}, s^{f}\right)$ is $\Gamma_{\mathbf{s}}$.

Each individual works during the first $R$ periods of his/her life. We assume that all working-age individuals are married. Individuals retire at age $R+1$ and become subject to survival risk. Thus retired households consist of either married couples, widows or widowers. Marital status of a household is described by the variable $d$ : $d=0$ for married, $d=1$ for a widow and $d=2$ for a widower. Individuals die no later than at age $J$.

\subsection{The Structure of Uncertainty}

The sources of uncertainty vary by age. Working individuals are only exposed to earnings risk. At retirement, individuals face survival and health risk and households face medical expense risk. We describe each of these risks in detail.

Individual productivity evolves over the working period according to functions $\Omega^{i}\left(j, \varepsilon_{\boldsymbol{e}}, s^{i}\right)$, $i \in\{m, f\}$, that map individual age $j$, household earning shocks $\varepsilon_{e} \equiv\left(\varepsilon_{e}^{m}, \varepsilon_{e}^{f}\right)$ and education type $s^{i}$ into efficiency units of labor. The vector of household earning shocks $\varepsilon_{\boldsymbol{e}}$ follows an 
age-invariant Markov process with transition probabilities given by $\Lambda_{e e^{\prime}}$. Efficiency units of newborn households are distributed according to $\Gamma_{e}$.

Starting at retirement, individuals face uncertainty about their health. An individual's health status, $h^{i}$, takes on one of two values: good $\left(h^{i}=g\right)$ and bad $\left(h^{i}=b\right)$. The probability of having good health next period, $\nu_{j}^{i}(h, d)$, depends on age, gender, current health status and marital status. The initial distribution of health status, $\Gamma_{h}^{i}\left(s^{i}\right)$, depends on the individual's education. Finally, denote a household's health status by $\mathbf{h} \equiv\left(h^{m}, h^{f}\right)$.

Medical and long-term care expenses are incurred at the household level and evolve stochastically according to the function $\Phi\left(j, \mathbf{h}, \boldsymbol{\varepsilon}_{\boldsymbol{M}}, d\right)$ that depends on household age $j$, household health status $\mathbf{h}$, the vector of medical expense shocks $\boldsymbol{\varepsilon}_{\boldsymbol{M}}$ and demographic status d. There are two medical expense shocks. The first shock follows an age-invariant Markov process with transition probabilities $\Lambda_{M M^{\prime}}$ and initial distribution $\Gamma_{M_{1}}$. The second shock is a transient, iid shock with probability distribution $\Gamma_{M_{2}}$.

Upon reaching retirement age, individuals face survival risk. This risk has two components. First, there is a death shock at age 65 which depends on that individual's lifetime earnings if male and their spouse's if female. This shock is used when calibrating the model to pin-down the age-65, marital status distribution $\Gamma_{d}(\bar{e})$. The rationale for this assumption is discussed in more detail in Section 4.1.3. Second, once retired, the probability of surviving to age $j+1$ conditional on surviving to age $j$ is given by $\pi_{j}^{i}(h, d)$ and depends on age, gender, health status and marital status.

Given these definitions, denote the survival rate from $j-1$ to age $j$ of a household with health and marital status of $(\mathbf{h}, d)$ by $\lambda_{j}(\mathbf{h}, d)$. The laws of motion for $\lambda_{j}(\mathbf{h}, d)$ are provided in the Appendix. It follows that the size of cohort $j$ is given by

$$
\eta_{j}=\eta_{j-1} \sum_{\mathbf{h}} \sum_{d} \lambda_{j}^{d}(\mathbf{h}, d), \text { for } j=2,3, \ldots, J
$$

\subsection{Government}

The government uses revenues from corporate, payroll and income taxes to finance SS payments, means-tested transfers and government expenditures, $G$.

\subsubsection{Social Security}

Currently, the U.S. Social Security system levies a payroll tax and uses its revenues to pay full benefits to eligible workers who retire at age 65. The program also provides benefits to 
spouses and survivors of eligible workers. We model SS as a pay-as-you go system.

Benefits In order to capture the spousal and survivor benefits, we assume that the benefit function $S(\overline{\mathbf{e}}, d)$ depends on lifetime earnings of both household members, $\overline{\mathbf{e}}$ and the household's current marital status, $d$. The specific benefit formula is reported in the Appendix. We note here that it captures the following features of the U.S. Social Security system. First, married couples have the option of either receiving their own benefits or 1.5 times the benefit of the highest earner in the household. Second, widows/widowers have the choice of taking their own benefit or their dead spouses benefit.

Sources of Finance The tax that finances SS benefits in the U.S. is a proportional tax levied on individual earnings, or payroll, up to a specified ceiling. In our model, this payroll tax is reflected by function $\tau_{s s}(\cdot)$, which we calibrate consistently with the U.S. Social Security system.

\subsubsection{Medicaid and Other Means-Tested Programs}

Benefits Medicaid has grown into the largest means-tested program in the U.S. Its primary beneficiaries are the elderly, the disabled, children and single women with children. The focus of this paper is on Medicaid and other means-tested welfare for the elderly, so we discuss benefits to the elderly first.

General guidelines for Medicaid benefits for the elderly are determined by the Federal government. However, states establish and administer their own Medicaid programs and determine the scope of coverage. For example, most states require copayments. The size of copayments varies depending on the type and amount of the expense incurred. In addition, some States cover prescription drugs, hearing aids and eye glasses, other States do not. A result is that many Medicaid recipients still have significant OOP expenses. ${ }^{5}$

Retirees may qualify for other means-tested welfare benefits including Supplemental Social Security Income, subsidized housing, food stamps and energy assistance. The federal government determines the Supplemental Social Security Income eligibility and most states use the same means test to determine eligibility for Medicaid and other state-run welfare programs. We choose to model these programs using a single means-tested transfer:

\footnotetext{
${ }^{5} \mathrm{~A}$ third reason that we see significant OOP expenses is that there is a medically needy path to Medicaid. See De Nardi, French and Jones (2012) for more discussion of this path to Medicaid.
} 


$$
\operatorname{Tr}^{R} \equiv \begin{cases}\max \left\{\underline{y}^{d}+\varphi M-I^{R}, \underline{c}^{d}+M-I^{R}, 0\right\}, & \text { if } \underline{y}^{d}>I^{R}-M \\ 0, & \text { otherwise. }\end{cases}
$$

Equation 1 describes the various situations that a retired household can find itself in. If its cash-in-hand, $I^{R}$, net of medical expenses, $M$, exceeds the means-test income threshold $\underline{y}^{d}$, the household receives no Medicaid benefits. If the household's cash-in-hand net of medical expenses falls below $\underline{y}^{d}$, it does receive a Medicaid benefit but is responsible for a Medicaid copayment of $(1-\varphi) M$. However, we cap this copayment in a way that insures that the household's consumption is at least $\underline{c}^{d}$.

In our model working households do not face medical expenses. We thus abstract from Medicaid for them. However, working households do face earnings risk and we model meanstested transfers that are a stand-in for programs such as unemployment insurance and foodstamps. Let $I^{W}$ denote cash-in-hand for a working household, then the transfer is

$$
\operatorname{Tr}^{W} \equiv \max \left\{0, \underline{c}-I^{W}\right\}
$$

where $\underline{c}$ is the consumption floor.

Sources of Finance Medicaid and other means-tested social welfare programs are jointly financed by states and the federal government using a variety of revenue sources. In the model, we assume that all funding for means-tested transfers comes out of general government revenues.

\subsubsection{Medicare and Government Purchases}

Medicare outlays are financed by a payroll tax $\tau_{m c}$. It follows that total payroll taxes are $\tau_{e}(e)=\tau_{s s}(e)+\tau_{m c}(e)$. We do not formally model the distribution of Medicare benefits. The main reason for this is a lack of data on individual or household level Medicare benefits. HRS only reports post-Medicare OOP medical expenses. In our model, medical expenses covered by Medicare are included in government purchases, $G$, instead.

The government budget is balanced period-by-period. It follows that revenues from the

corporate tax $\tau_{c}$, income taxes $T_{y}^{W}$ and $T_{y}^{R}$, and Medicare tax $\tau_{m c}(\cdot)$ finance means-tested transfers and $G$. 


\subsection{Household's Problem}

We start by describing the household's preferences. For married households, most of the variation in labor supply is due to changes in labor force participation and hours worked by the female (see e.g. Keane and Rogerson (2012) for a survey). For this reason, we abstract from the male labor supply decision but model both margins of labor supply by the female. We assume that households have preferences over consumption $c$ and non-market time of the female member $l_{f}$.

The utility function of a working household is given by

$$
U^{W}\left(c, l_{f}, \mathbf{s}\right)=2^{N-1} \frac{\left(c /(1+\chi)^{N-1}\right)^{1-\sigma}}{1-\sigma}+\psi(\mathbf{s}) \frac{l_{f}^{1-\gamma}}{1-\gamma}-\phi(\mathbf{s}) \mathbf{I}\left(l_{f}<1\right)
$$

where $N$ is the number of living household members ( $N=2$ for all working households), $\mathbf{I}$ is the indicator function, $\sigma, \gamma>0$ and $\psi(\mathbf{s}), \phi(\mathbf{s})>0$ for all $\mathbf{s}$. This specification of preferences assumes a unitary household in which each member is fully altruistic towards their spouse. The parameter $\chi \in[0,1]$ determines the degree to which consumption is joint within the household. For instance, when $\chi$ is 1 , all consumption is individual and when $\chi$ is 0 , all consumption is joint. The third term in the utility function captures the utility cost of female participation in the labor force. Modeling this cost helps us match both the intensive and extensive margins of female labor supply.

The utility function of a retired household with $N$ living members (determined by $d$ ) is defined similarly:

$$
U^{R}(c, d)=2^{N-1} \frac{\left(c /(1+\chi)^{N-1}\right)^{1-\sigma}}{1-\sigma}+\psi^{R} \frac{l_{f}^{1-\gamma}}{1-\gamma}
$$

where $l_{f}=1$ and $\psi^{R}>0$.

The constraints and decisions of working households and retired households are quite different. We thus describe each problem separately.

\subsubsection{Working Household's Problem}

A working household of age $j$ with education type $\mathbf{s} \equiv\left\{s^{m}, s^{f}\right\}$ enters each period with assets $a$ and average lifetime earnings of the male and female $\overline{\mathbf{e}} \equiv\left\{\bar{e}^{m}, \bar{e}^{f}\right\}$. It then receives the current labor productivity shocks $\varepsilon_{e} \equiv\left\{\varepsilon_{e}^{m}, \varepsilon_{e}^{f}\right\}$ and chooses consumption $c$, savings $a^{\prime}$ and female labor supply $l_{f}$. Let earnings be $e^{i}=w \Omega^{i}\left(j, \boldsymbol{\varepsilon}_{e}, s^{i}\right)\left(1-l \mathbf{I}_{i=f}\right), i \in\{m, f\}$. The 
optimal choices are given by the solution to the following problem:

$$
V^{W}\left(j, a, \overline{\mathbf{e}}, \boldsymbol{\varepsilon}_{\boldsymbol{e}}, \mathbf{s}\right)=\max _{c, l_{f}, a^{\prime}}\left\{U^{W}\left(c, l_{f}, \mathbf{s}\right)+\beta \mathbf{E}\left[V\left(j+1, a^{\prime}, \overline{\mathbf{e}}^{\prime}, \boldsymbol{\varepsilon}_{\boldsymbol{e}}^{\prime}, \mathbf{s}\right) \mid \varepsilon_{\boldsymbol{e}}\right]\right\}
$$

subject to the law of motion for $\varepsilon_{\boldsymbol{e}}$ and its initial distribution, as described in Section 3.2, and the following constraints:

$$
\begin{gathered}
c \geq 0, \quad 0 \leq l_{f} \leq 1, \quad a^{\prime} \geq 0, \\
\bar{e}^{i \prime}=\left(e^{i}+j \bar{e}^{i}\right) /(j+1), \quad i \in\{m, f\}, \\
c+a^{\prime}=a+y^{W}-T_{y}^{W}+\operatorname{Tr}^{W},
\end{gathered}
$$

where

$$
\begin{gathered}
y^{W} \equiv e^{m}+e^{f}+\left(1-\tau_{c}\right) r a \\
T_{y}^{W} \equiv \tau_{y}\left(y^{W}-\tau_{e}\left(e^{m}\right) e^{m}-\tau_{e}\left(e^{f}\right) e^{f}\right)+\tau_{e}\left(e^{m}\right) e^{m}+\tau_{e}\left(e^{f}\right) e^{f} \\
I^{W} \equiv a+y^{W}-T_{y}^{W} .
\end{gathered}
$$

Equation (6) describes regularity conditions on consumption and leisure and imposes a borrowing constraint which rules out uncollateralized lending. The dynamics of average lifetime earnings, which determine social security benefits, are given in (7) and the household budget constraint is given by (8). The definition for $\operatorname{Tr}^{W}$ is given in (2). Household income (9) has two components: labor income and capital income. Capital income is subject to a corporate $\operatorname{tax} \tau_{c}$, and (10) states that households also pay an income tax $\tau_{y}\left(\dot{)}\right.$ and a payroll tax, $\tau_{e}(e)$. Finally, (11) defines cash-in-hand.

\subsubsection{Retired Household's Problem}

During retirement the household's problem changes. Men and women spend all of their time endowment enjoying leisure. Retirees face health, medical expense and survival risk.

We will assume that individuals observe their own and their spouses death event one period in advance. It follows that bequests are zero for households with a single member. 
This assumption has the following motivations. First, there is considerable evidence that bequests and inheritances are low. One reason for this is that wealth is low in the final year of life. Poterba, Wise and Venti (2012) find that many individuals die with very low levels of assets. They report that $46.1 \%$ of individuals have less than $\$ 10,000$ in financial assets in the last year observed before death and $50 \%$ have zero home equity using data from HRS. In a separate study of the Survey of Consumer Finances (SCF) Hendricks (2001) reports direct measurements of inheritances. He finds that most households receive very small or no inheritances. Fewer than $10 \%$ of households receive an inheritance larger than two mean annual earnings and the top $2 \%$ account for $70 \%$ of all inheritances.

The second reason for this assumption is that it allows us to capture the fact that both OOP and Medicaid medical expenses are large in the final year of life. In our HRS sample of retirees, OOP expenses in the last year of life are 3.43 times as large as OOP expenses in other years. Medicaid expenditures are not available in our dataset. However, Hoover et al. (2002) report that in final year of life Medicaid expenditures are $25 \%$ of total Medicaid expenditures for those aged 65 and older. This result is based on Medicare Beneficiary Survey data from 1992-1996.

An attractive outcome of this assumption is that accidental bequests are zero. Previous research has found that the pattern of redistribution of accidental bequests has important incentive effects. Changes in government policy that alter the size and distribution of these bequests have big incentive effects and this acts to muddle any analysis of the welfare effects of policy reform. For examples of this see Kopecky and Koreshkova (2007) and Hong and Ríos (2007).

For retirees the household's education type is no longer a state variable. Education does enter indirectly since the initial distribution of individual health status varies with educational attainment. Health, and thus education, affect both individual survival probabilities and household medical expenses as described in Section 3.2.

The probability that an age- $j$ individual of gender $i$ with health status $h^{i}$ and marital status $d$ survives to age $j+1$ is denoted by $\pi_{j+1}^{i}\left(h^{i}, d\right)$. It follows that an age- $j$ household faces survival probabilities $\pi_{j}\left(d^{\prime} \mid \mathbf{h}, d\right)$ given by

\begin{tabular}{|c|c|c|c|}
\hline & $d^{\prime}=0$ & $d^{\prime}=1$ & $d^{\prime}=2$ \\
\hline$d=0$ & $\pi_{j+1}^{m}\left(h^{m}, 0\right) \pi_{j+1}^{f}\left(h^{f}, 0\right)$ & {$\left[1-\pi_{j+1}^{m}\left(h^{m}, 0\right)\right] \pi_{j+1}^{f}\left(h^{f}, 0\right)$} & $\pi_{j+1}^{m}\left(h^{m}, 0\right)\left[1-\pi_{j+1}^{f}\left(h^{f}, 0\right)\right.$ \\
\hline$d=1$ & 0 & $\pi_{j+1}^{f}\left(h^{f}, 1\right)$ & 0 \\
\hline$d=2$ & 0 & 0 & $\pi_{j+1}^{m}\left(h^{m}, 2\right)$ \\
\hline
\end{tabular}

An age- $j$ household with assets $a$, average lifetime earnings $\overline{\mathbf{e}}$, health $\mathbf{h}$, medical expense 
shock $\varepsilon_{\boldsymbol{M}}$, current demographic status $d$ and next period demographic status $d^{\prime}$ chooses $c$ and $a^{\prime}$ by solving

$V^{R}\left(j, a, \overline{\mathbf{e}}, \mathbf{h}, \boldsymbol{\varepsilon}_{\boldsymbol{M}}, d, d^{\prime}\right)=\max _{c, a^{\prime}}\left\{U^{R}(c, d)+\beta \mathbf{E}\left[\sum_{d^{\prime \prime}=0}^{2} \pi_{j}\left(d^{\prime \prime} \mid \mathbf{h}^{\prime}, d^{\prime}\right) V\left(j+1, a^{\prime}, \overline{\mathbf{e}}, \mathbf{h}^{\prime}, \varepsilon_{M}^{\prime}, d^{\prime}, d^{\prime \prime}\right) \mid \mathbf{h}, \boldsymbol{\varepsilon}_{\boldsymbol{M}}\right]\right\}$

subject to the laws of motion for $\mathbf{h}, \boldsymbol{\varepsilon}_{\boldsymbol{M}}$ and their initial distributions, as described in Section 3.2 and the following constraints:

$$
\begin{gathered}
c \geq 0, \quad a^{\prime} \geq 0, \\
c+M+a^{\prime}=a+y^{R}-T_{y}^{R}+T r^{R},
\end{gathered}
$$

where

$$
\begin{gathered}
M \equiv \Phi\left(j, \mathbf{h}, \boldsymbol{\varepsilon}_{\boldsymbol{M}}, d, d^{\prime}\right), \\
y^{R} \equiv S(\overline{\mathbf{e}}, d)+\left(1-\tau_{c}\right) r a, \\
T_{y}^{R} \equiv \tau_{y}^{R}\left(\left(1-\tau_{c}\right) a r, S(\overline{\mathbf{e}}, d), d, M\right), \\
I^{R} \equiv a+y^{R}-T_{y}^{R},
\end{gathered}
$$

and the expectations operator $\mathbf{E}$ is taken over $\varepsilon_{\boldsymbol{M}}^{\prime}$ and $\mathbf{h}^{\prime}$. The means-tested transfer $\operatorname{Tr}^{R}$ is defined in equation (1).

The main differences between the working household's problem and the retired household's problem are as follows. Medical expenses $M$ now enter the household's budget constraint (14). Households have no labor income but instead may receive social security benefits. Retired households also face a nonlinear income tax schedule. In particular, their social security benefits are also subject to income taxation if these benefits exceed the exemption level specified in the U.S. tax code. We also allow for a deduction of medical expenses that exceed $\kappa$ percent of taxable income. The specific formulas used to compute income taxes are reported in the appendix. 


\subsubsection{Problem for a Household about to Retire}

The previous two cases cover all situations except that of a household in its last working period, $R$. Such a household enters the period with the state variables of a working household and chooses consumption, savings and female labor supply, recognizing that in period $R+1$ it will face the problem of a retired household. Consequently, when evaluating next period's value function, they form expectations using the distributions $\Gamma_{h}^{m}, \Gamma_{h}^{f}, \Gamma_{M_{1}}, \Gamma_{M_{2}}$ and $\Gamma_{d}\left(\bar{e}^{m}\right)$.

\subsection{Technology}

Competitive firms produce a single homogeneous good by combining capital $K$ and labor $L$ using a constant-returns-to-scale production technology:

$$
Y \equiv F(K, L)=A K^{\alpha} L^{1-\alpha}
$$

and rent capital and labor in perfectly competitive factor markets. The aggregate resource constraint is given by

$$
Y+(r+\delta)(\bar{K}-K)=C+(1+n) \bar{K}^{\prime}-(1-\delta) \bar{K}+\tilde{M}+G
$$

where $\bar{K}$ is per capita private wealth, $C$ denotes per capita consumption, $\tilde{M}$ is per capita medical expenses, $G$ is government purchases and $\delta$ is the depreciation rate on capital.

\subsection{General Equilibrium}

We consider a steady-state competitive equilibrium for a small open economy. ${ }^{6}$ For the purposes of defining an equilibrium in a compact way, we suppress the individual state into a vector $(j, x, d, E)$, where

$$
x= \begin{cases}x_{W} \equiv\left(a, \overline{\mathbf{e}}, \varepsilon_{\boldsymbol{e}}, \mathbf{s}\right), & \text { if } 1 \leq j \leq R \\ x_{R} \equiv\left(a, \overline{\mathbf{e}}, \mathbf{h}, \boldsymbol{\varepsilon}_{\boldsymbol{M}}, d, d^{\prime}\right), & \text { if } R<j \leq J\end{cases}
$$

Accordingly, we redefine value functions, decision rules, income taxes, means-tested transfers and SS benefits to be functions of the individual state $(j, x): V^{W}(j, x), V^{R}(j, x), c(j, x)$,

\footnotetext{
${ }^{6}$ Even though the U.S. is a large economy, capital markets are integrated and thus it is not clear how important changes in domestic savings are for determination of the real interest rate. We therefore choose to hold the real interest rate fixed.
} 
$a^{\prime}(j, x), l_{f}\left(j, x_{W}\right), T_{y}(x), \operatorname{Tr}(j, x)$ and $S\left(x_{R}\right)$. Define the individual state spaces:

$$
\begin{aligned}
& X_{W} \subset[0, \infty) \times[0, \infty) \times[0, \infty) \times\{(h s, h s),(h s, c o l),(\text { col }, h s),(\text { col }, \text { col })\}, \\
& X_{R} \subset[0, \infty) \times[0, \infty) \times\{(g, g),(b, g),(g, b),(b, b)\} \times[0, \infty) \times\{0,1,2\} \times\{0,1,2\} .
\end{aligned}
$$

and denote by $\Xi(X)$ the Borel $\sigma$-algebra on $X \in\left\{X_{W}, X_{R}\right\}$. Let $\Psi_{j}(X)$ be a probability measure of individuals with state $x \in X$ in cohort $j$. Note that these agents constitute a fraction $\eta_{j} \Psi_{j}^{d}(X)$ of the total population.

DEFINITION. Given a fiscal policy $\left\{S(\overline{\mathbf{e}}, d), G, \tau_{c}, \tau_{m c}(e), \underline{c}^{d}, \underline{y}^{d}, \kappa\right\}$ and a real interest rate $r$, a steady-state competitive equilibrium consists of household policies $\left\{c(j, x), a^{\prime}(j, x), l_{f}(j, x)\right\}_{j=1}^{J}$ and associated value functions $\left\{V^{W}(j, x)\right\}_{j=1}^{R},\left\{V^{R}(j, x)\right\}_{j=R+1}^{J}$, taxes and prices $\left\{\tau_{s s}(e), T_{y}(x), w\right\}$, per capita capital stocks $\{\bar{K}, K\}$ and an invariant distribution $\left\{\Psi_{j}\right\}_{j=1}^{J}$ such that

1. At the given prices and taxes, the household policy functions $c(j, x), a^{\prime}(j, x)$ and $l(j, x)$ achieve the value functions.

2. At the given prices, firms are on their input demand schedules: $w=F_{L}(K, L)$ and $r=F_{K}(K, L)-\delta$.

3. Aggregate savings are given by $\sum_{j} \eta_{j} \int_{X} a^{\prime}(j, x) d \Psi_{j}=(1+n) \bar{K}$.

4. Markets clear:

(a) Goods $\sum_{j} \eta_{j} \int_{X} c(j, x) d \Psi_{j}+(1+n) \bar{K}+\tilde{M}+G=F(K, L)+(1-\delta) \bar{K}+r(\bar{K}-K)$, where $\tilde{M}=\sum_{j=R}^{J} \eta_{j} \int_{X_{R}} \Phi\left(j, \mathbf{h}, \varepsilon_{\boldsymbol{M}}, d, d^{\prime}\right) d \Psi_{j}$.

(b) Labor: $\sum_{j} \eta_{j} \int_{X}\left\{\left(1-l_{f}(j, x)\right) \Omega^{f}\left(j, \varepsilon_{\boldsymbol{e}}, s^{f}\right)+\Omega^{m}\left(j, \boldsymbol{\varepsilon}_{\boldsymbol{e}}, s^{m}\right)\right\} d \Psi_{j}=L$.

5. Distributions of agents are consistent with individual behavior:

$$
\Psi_{j+1}\left(X_{0}\right)=\int_{X_{0}}\left\{\int_{X} Q_{j}\left(x, x^{\prime}\right) \mathbf{I}_{j^{\prime}=j+1} d \Psi_{j}\right\} d x^{\prime}
$$

for all $X_{0} \in \Xi$, where $\mathbf{I}$ is an indicator function and $Q_{j}\left(x, x^{\prime}\right)$ is the probability that an agent of age $j$ and current state $x$ transits to state $x^{\prime}$ in the following period. (A formal definition of $Q_{j}\left(x, x^{\prime}\right)$ is provided in the Appendix.)

6. SS budget is balanced: SSbenefits = PayrollTaxes, where

$$
\text { SSbenefits }=\sum_{j=R+1}^{J} \eta_{j} \int_{X_{R}} S(x) d \Psi_{j}
$$


and

$$
\text { PayrollTaxes }=\sum_{j=1}^{R} \eta_{j} \int_{X_{W}}\left\{\tau_{s s}\left(e^{m}(j, x)\right) e^{m}(j, x)+\tau_{s s}\left(e^{f}(j, x)\right) e^{f}(j, x)\right\} d \Psi_{j}
$$

7. The government's budget is balanced:

$$
\text { IncomeTaxes }+ \text { CorporateTaxes }+ \text { MedicareTaxes }=\text { Transfers }+G
$$

where income tax revenue is given by

$$
\text { IncomeTaxes }=\sum_{j=1}^{J} \eta_{j} \int_{X} T_{y}(x) d \Psi_{j}
$$

corporate profits tax revenue is

$$
\text { CorporateTaxes }=\sum_{j=1}^{R} \eta_{j} \int_{X_{W}} \tau_{c} r a(j, x) d \Psi_{j}
$$

and Medicare tax revenue is

$$
\text { MedicareTaxes }=\sum_{j=1}^{R} \eta_{j} \int_{X_{W}}\left\{\tau_{m c}\left(e^{m}(j, x)\right) e^{m}(j, x)+\tau_{m c}\left(e^{f}(j, x)\right) e^{f}(j, x)\right\} d \Psi_{j}
$$

and means-tested transfer payments are

$$
\text { Transfers }=\sum_{j=1}^{J} \eta_{j} \int_{X} \operatorname{Tr}(j, x) d \Psi_{j}
$$

\section{Calibration}

The model is parameterized to match a set of aggregate and distributional moments for the U.S. economy, including demographics, earnings, medical and nursing home expenses, as well as features of the U.S. social welfare, Medicaid, social security and income tax systems. Some of the parameter values can be determined ex-ante, others are calibrated by making the moments generated by a stationary equilibrium of the model target corresponding moments in the data. The calibration procedure minimizes the differences between the data targets 


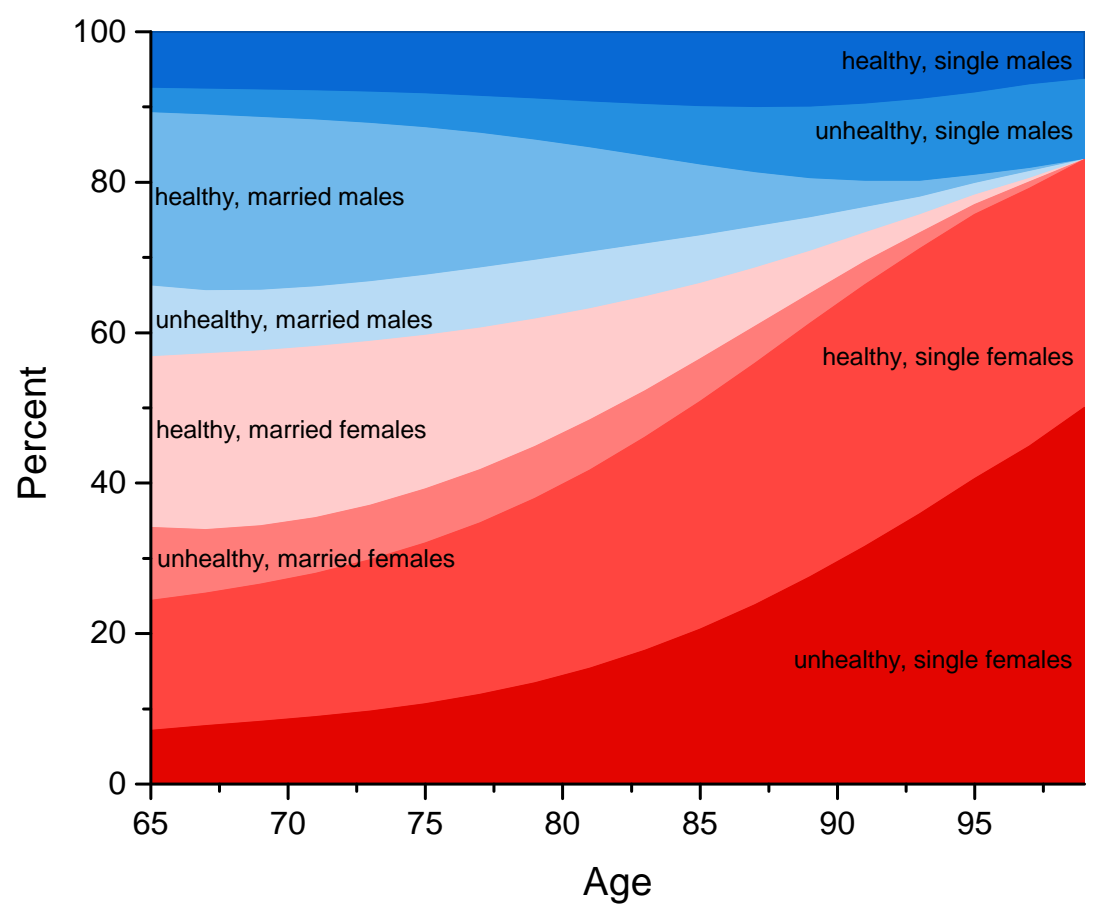

Figure 1: The population distribution of retirees by age. Individuals are classified by gender, health and marital status. The data for this figure is our HRS sample.

and model's predicted values. ${ }^{7}$ We focus in this section on the most important aspects of the calibration. Additional calibration details are proved in Section 8.3.

\subsection{Demographics}

This section reports how we calibrate the parameters of the model that pertain to demographics. Agents are born at age 21 and can live to a maximum age of 100 . Given that the focus of our analysis is on retirees, we want to reproduce the demographic structure of those 65 and older. Figure 1 reports the evolution of the distribution of retirees by marital status, health and gender estimated from our HRS sample. At the beginning of retirement, half of the population is healthy and married. As individuals age, three things happen: the fraction of singles increases, the fraction of unhealthy increases and males die faster than females. Below we will describe how we estimate this demographic structure and build it into our model.

\footnotetext{
${ }^{7}$ Due to the computational complexity of the model it is not feasible to implement a formal method-ofmoments estimation strategy.
} 


\subsubsection{Age Structure}

We set the model period to two years because the data on OOP medical expenses is only available bi-annually. The maximum life span is $J=40$ periods. Agents work for the first 44 years of life, i.e. the first 22 periods. At the beginning of period $R+1=23$, they retire and begin to face survival risk.

The target for the population growth rate $n$ is the ratio of population 65 years old and over to that 21 years old and over. According to U.S. Census Bureau, this ratio was 0.18 in 2000. We target this ratio rather than directly setting the population growth rate because the weight of the retired in the population determines the tax burden on workers, which is an object of primary interest in our policy analysis. The resulting annual growth rate of population is 1.8 percent.

\subsubsection{Education}

Newborn are endowed with either high school or college educational attainment which is fixed throughout their working life. The model distribution of schooling types is set to reproduce its empirical counterpart in our HRS data sample for 65-66 year-old married households. In our data, both spouses have college degrees in 14 percent of households, in 14 percent only the male has a college degree, in 5 percent only the female has a college degree, and in 67 percent neither spouse has a college degree.

\subsubsection{Marital Status}

Newborn are matched with a spouse and remain married until at least age 65. In our HRS sample, only 48 percent of 65-66 year-olds households are married couples, 36 percent are single females and 16 percent are single males. For the most part, these figures reflect the cumulative effects of divorce and spousal death in the ages prior to age 65. Since our primary objective is to model retirees, we summarize these effects with a spousal death event at age 65. This event, which is distinct from the health-related survival risk agents face throughout retirement, ensures that $\Gamma_{d}(\bar{e})$ reproduces the marital status distribution of 65 year-olds in the data.

Another feature of our HRS data is that social-security income varies with martial status. Table 7 shows that there are very large differences in social security benefits across the three types of households. Married households have the highest benefits and single males receive higher benefits than females. In order to reproduce these observations, we assume that the spousal death shock has a negative relation with the distribution of average life-time earnings of the male. We then calibrate the death shock so that it reproduces the fractions of married, 
Table 7: Marital status distribution of households with 65-66 year-old household heads by social security benefit quintiles

\begin{tabular}{l|ccccc}
\hline \hline & \multicolumn{5}{|c}{ Quintile } \\
& 1 & 2 & 3 & 4 & 5 \\
\hline Married & 0.19 & 0.24 & 0.36 & 0.67 & 0.95 \\
Single Female & 0.56 & 0.55 & 0.45 & 0.21 & 0.03 \\
Single Male & 0.25 & 0.21 & 0.20 & 0.12 & 0.02 \\
\hline \hline
\end{tabular}

The fraction of households in each social security income quintile who are married, single female or single male households. Authors' computations. Data: 1995-2010 HRS/AHEAD retired households aged 65+. See 8.1.1 for more details.

single male and single female households by social security benefit quintiles shown in Table 7.

\subsubsection{Survival Probabilities and Health Status}

Table 8 reports estimates of expected remaining years of life for 65 -year-old individuals by marital status, health status and gender. All three factors have large effects on longevity. Having a spouse at age 65 is particularly beneficial for males extending their longevity by 2.9 years compared to 1.7 years for females. Good health extends life by about five years for both genders. Finally, females live on average 2.9 years longer than males.

These results are based on estimated survival probabilities, $\pi_{j+1}^{i}\left(h^{i}, d\right)$, for males and females from our HRS sample. Survival probabilities are assumed to be a logistic function of age, age-squared, health status, marital status, health status interacted with age and marital status interacted with age. Transition probabilities for health status are also estimated separately for males and females, using the same logistic functions. The initial distributions of individuals across health status at age $65, \Gamma_{h}^{i}\left(s^{i}\right)$, are set to match the distribution of health status by education in the HRS sample for 65-66 year-olds.

\subsection{Medical Expense Process}

Medical expenses vary systematically with age, gender, health and marital status. Moreover, when motivating our model, we found evidence that suggested medical expense shocks are important sources of impoverishment for retirees. We assume the medical expenses have a deterministic and stochastic component. We now describe each of these components. 
Table 8: Expected additional years of life at age 65 by health status, marital status and gender

\begin{tabular}{lccc}
\hline \hline & Female & Male & All \\
\hline & 19.5 & 16.6 & 18.2 \\
By health & & & \\
$\quad$ good & 20.5 & 17.6 & 19.2 \\
bad & 15.8 & 12.2 & 14.3 \\
By marital status & & \\
$\quad$ married & 20.1 & 17.2 & 18.6 \\
single & 18.4 & 14.3 & 17.0 \\
\hline \hline
\end{tabular}

Authors' computations. Data: 1995-2010 HRS/AHEAD retired households aged 65+. See 8.1.1 for more details on the data. Note that life expectancies in our HRS sample are lower than those in the 2000 U.S. Census. We thus scaled up the survival probabilities to match Census life expectancies at age 65 .

\subsubsection{Deterministic Medical Expense Profiles}

In the model, medical expenses are household-specific. We start by estimating deterministic medical expense profiles for individuals and then sum these expenses over spouses for married couples. The shape of the medical expense profiles is determined by regressing individual medical expenses on a quartic in age and a quartic in age interacted with gender, marital status, mortality status (a dummy variable that takes on the value of one if death occurs in the next period) and health status using a fixed-effects estimator. ${ }^{8}$

Our HRS data only reports household expenses paid out of pocket and not those covered by Medicaid. However, when solving the model, we need to specify pre-Medicaid medical expenses, defined as the sum of OOP and Medicaid payments. To resolve this issue, we exploit the fact that individuals in the top lifetime earnings quintile (or who have/had spouses in the top lifetime earnings quintile) are unlikely to be eligible for means-tested Medicaid transfers, and hence their OOP medical expenses are, on average, very close to their pre-Medicaid expenses. Thus, the control variables in our medical expense regression include permanent income quintile dummies and their age-interaction terms. These latter controls reduce the estimation bias arising from the fact that Medicaid transfers increase with age. The estimated coefficients from this regression for permanent earnings quintile 5 pin down the shape of the deterministic age-profile of the pre-Medicaid medical expense

\footnotetext{
${ }^{8}$ As pointed out by De Nardi et al. (2010), the fixed effects estimator overcomes the problem with the variation in the sample composition due to differential mortality as well as accounts for cohort effects.
} 


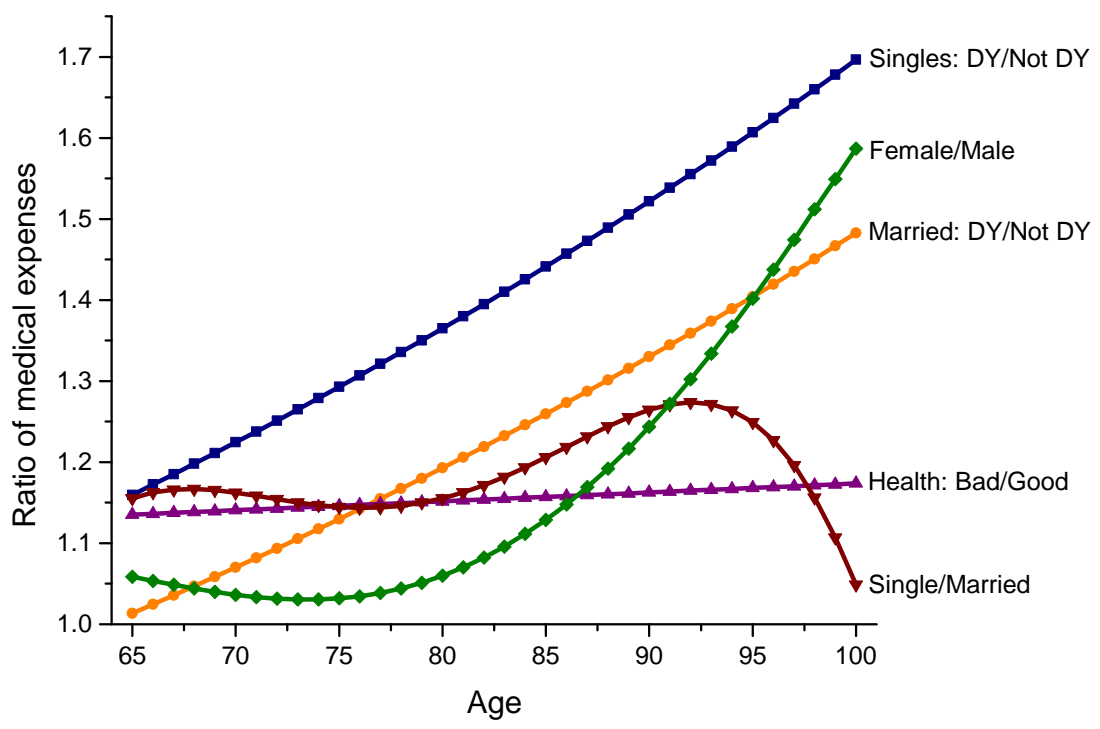

Figure 2: Estimated effects of marital status, health and death year (DY) conditional on marital status on individual medical expenses by age. The vertical axis is the ratio of estimated medical expenses for each type pair. Data: 1995-2010 HRS/AHEAD retired individuals aged $65+$. See 8.1 for more details.

process. $^{9}$

The obtained medical expense profiles are similar to profiles reported in De Nardi et al. (2010) and Kopecky and Koreshkova (2007). OOP expenses increase with permanent income and age. Moreover, OOP medical expenses are higher for females relative to males and higher if self-reported health status is poor.

Our estimated medical expense profiles also provide new information about how medical expenses vary by marital status and death year. Figure 2 shows the effects of marital status and death year on medical expenses. For purposes of comparison, we also report how medical expenses vary with gender and health. The most striking feature of the figure is that death year has a very large effect on medical expenses and its importance increases with age. At age 65 medical expenses for singles in their death year are 15\% higher than for singles not in their death year. By age 85 the difference has risen to $45 \%$. The effect of death year is smaller for married individuals but still important. A second result is that the effect of marital status on medical expenditures is as large as or larger than the effect of health for those under age 95 .

\footnotetext{
${ }^{9}$ All of the coefficients documented here are significant at conventional significance levels. Estimated coefficients and standard errors from these regressions are available upon request.
} 


\subsubsection{Stochastic Structure of Medical Expenses}

The stochastic component of medical expenses has a persistent and a transitory component. The standard deviation of the transitory component is 0.816 and the persistent component is assumed to follow an $\mathrm{AR}(1)$ at annual frequencies with an autocorrelation coefficient of 0.922 and a standard deviation of 0.579. These values are taken from French and Jones (2004). ${ }^{10}$ The initial distribution of the persistent medical expense shock, $\Gamma_{M_{1}}$, is set to the distribution of OOP expenses at age 65-66 in our HRS data sample.

Previous work has found that an important source of variation in retirees medical expenses is long-term care needs. ${ }^{11}$ To capture long-term care risk, we approximate the persistent shock with a five state Markov chain. In particular, we assume that the fifth state is associated with nursing home care. This calibration of the Markov chain captures both the small variation in medical expenses due to acute costs and the large variation due to long-term care costs. In particular, we target data facts pertaining to expected duration of nursing home stays, the distribution of age at first entry and overall size of nursing home expenses. The resulting Markov process recovers the serial correlation and standard deviation of the $\mathrm{AR}(1)$ process but is not Gaussian. More details on this aspect of the calibration are reported in 8.3.1.

Finally, we scale the medical expense profiles so that aggregate medical expenditures in the model are $2.1 \%$ of GDP. This target corresponds to the average total expenditures on medical care paid OOP or by Medicaid during the period 1999 to $2005 .{ }^{12}$

\subsection{Government}

We divide our discussion of the calibration of fiscal policy variables into two parts. We start by discussing calibration of the sources of government revenue and then turn to discuss the uses of government revenue.

\subsubsection{Sources of Government Revenue}

The government raises revenue from three taxes: a proportionate corporate profits tax, and nonlinear income and payroll taxes. We choose the size of the corporate profits tax and income taxes to reproduce the revenues of each of these taxes expressed as a fraction of

\footnotetext{
${ }^{10}$ Their estimates are based on individuals. We use these values for the household but assume that the medical expense shocks to husbands and wives are independent.

${ }^{11}$ See for example Kopecky and Koreshkova (2007) who find that nursing home expenses are important drivers of life-cycle savings.

${ }^{12}$ Total medical expenditures paid OOP or by Medicaid are taken from the "National Health Expenditure Accounts," U.S. Centers for Medicare and Medicaid Services and include payments for insurance premia.
} 
GDP in U.S. data. The specific targets are $2.8 \%$ of GDP for the corporate profits tax and 8\% of GDP for the income tax. These targets are averages over years 1950-2008 as reported in Table 11 of "Present Law and Historical Overview of the Federal Tax System."

U.S. income tax schedules vary with marital status. In our model, all workers are married but retirees can be single or married. Using the IRS Statistics of Income Public Use Tax File for the year 2000, Guner, Kaygusuz and Ventura (2012) estimate effective income tax functions for both married households and singles following the methodology of Kaygusuz (2010). We use their estimates (see Section 8.3.5 for more details.).

Contributions for SS and Medicare are financed by the payroll tax, $\tau_{e}=\tau_{s s}+\tau_{m c}$. The SS component of this tax, $\tau_{s s}$ is subject to a cap. We set the cap to be twice average earnings. This choice reproduces the cap of $\$ 72,000$ for the year 2000 in U.S. data. The Medicare component of this tax, $\tau_{m c}$, is set to the total (employee + employer) Medicare tax rate which in year 2000 was equal to $2.3 \%$.

\subsubsection{Uses of Government Revenue}

Recall that the government has three principal uses of funds: it pays social security benefits to retirees, provides means-tested social welfare benefits, and purchases goods and services from the private sector. We discuss the calibration of each of these types of expenditures in turn. The social security benefit function in our model reproduces the progressivity of the U.S. social security system and provides spousal and survivor benefits (see 8.3.6 for details).

The welfare program in our model represents public assistance programs in the U.S., including Medicaid, Supplemental Social Security Income, food stamps, unemployment insurance, Aid to Families with Dependent Children, and energy and housing assistance programs. For working individuals, we set the consumption floor, $\underline{c}$, in equation (2) to $15 \%$ of average earnings of full-time, prime-age, male workers. In year 2000 dollars, this is approximately $\$ 7,100$. This magnitude is consistent with estimates from the previous literature. ${ }^{13}$

The means-test income thresholds $\underline{y}^{d}$ and consumption floors $\underline{c}^{d}$, of retirees vary with marital status. We set the consumption floors to $1 / 2$ the level of the income thresholds and then set the income thresholds to target Medicaid take-up rates for retirees in our HRS dataset. The values of the targets are $22 \%$ for widows, $17 \%$ for widowers and $7 \%$ for married individuals. The resulting means-test income thresholds are close to $32 \%$ of average earnings of full-time, prime-age, male workers for all three types of individuals. ${ }^{14}$ That is, they are approximately $\$ 15,200$ in year 2000 dollars. It follows that the consumption floors for retirees are about $16 \%$ of male average earnings or approximately $\$ 7,600$. The target for

\footnotetext{
${ }^{13}$ See Kopecky in Koreshkova (2007) for a discussion of the literature on consumption floors.

${ }^{14}$ The precise values are $\underline{y}^{0}=0.31, \underline{y}^{1}=0.33$ and $\underline{y}^{2}=0.32$.
} 
Table 9: Medicaid take-up rates by age and marital status

\begin{tabular}{cccc}
\hline \hline Age & $65-74$ & $75-84$ & $85+$ \\
\hline $\begin{array}{l}\text { Marital Status } \\
\text { Married }\end{array}$ & & & \\
$\quad$ data & 0.07 & 0.07 & 0.11 \\
model & 0.05 & 0.07 & 0.12 \\
Widows & & & \\
data & 0.22 & 0.19 & 0.24 \\
model & 0.21 & 0.23 & 0.25 \\
Widowers & & & \\
data & 0.19 & 0.15 & 0.19 \\
model & 0.17 & 0.16 & 0.17 \\
\hline \hline
\end{tabular}

The fraction of individuals receiving Medicaid transfers by age group and marital status in the data and the model. Data: 1995-2010 HRS/AHEAD retired individuals aged 65+. See 8.1 for more details.

the Medicaid copay rate, $(1-\varphi)$, is the ratio of average OOP medical expenses of Medicaid recipients to average OOP medical expenses of all retirees. In our HRS sample, this ratio is 0.46. The resulting copay rate is $20 \%$.

Finally, we adjust government purchases, $G$, of goods and services to close the government budget constraint. This results in a $G / Y$ ratio of 0.11 for our baseline parameterization of the model.

\section{Assessment of Baseline Calibration}

In this section we compare some moments from the model with the data that were not targeted when parameterizing the model. We start by showing that the model delivers patterns close to the data on Medicaid take-up rates, flows into Medicaid and OOP medical expenses by age and marital status. Then we show that the model delivers an increased likelihood of impoverishment for individuals with large acute and long-term care OOP expenses, bad health status and those whose spouse has died, in line with the evidence on impoverishment documented in Section 2.

\subsection{Medicaid Take-up Rates and Flows}

We start by discussing Medicaid take-up rates. In calibrating the model, we set the consumption floors to reproduce the fractions of each type of retired household on Medicaid. 
Table 10: Bi-annual Flows into Medicaid by Age and Marital Status

\begin{tabular}{cccc}
\hline \hline Age & $65-74$ & $75-84$ & $85+$ \\
\hline $\begin{array}{c}\text { Marital Status } \\
\text { Married }\end{array}$ & & & \\
data & 0.028 & 0.029 & 0.043 \\
model & 0.021 & 0.023 & 0.040 \\
Widows & & & \\
data & 0.065 & 0.055 & 0.088 \\
model & 0.089 & 0.050 & 0.051 \\
Widowers & & & \\
data & 0.077 & 0.066 & 0.090 \\
model & 0.078 & 0.056 & 0.061 \\
\hline \hline
\end{tabular}

The flows are the fraction of retirees with given initial marital status not receiving Medicaid but who become recipients over the next two years. Data: 1995-2010 HRS/AHEAD retired individuals aged 65+. See 8.1 for more details.

The Medicaid take-up rates by age were not explicitly targeted and thus are a way to assess the model's performance. Table 9 compares the take-up rates of Medicaid by age for the three household types. Inspection of Table 9 indicates that the model does a good job of reproducing Medicaid take-up rates for each age group.

Another implication of the model that was not targeted is flows into Medicaid. Table 10 reports flows into Medicaid by age and marital status. Observe that in the data, the flows into Medicaid are much lower for married than singles. Moreover, the flows increase monotonically with age for married but follow a U-shaped pattern for singles. Model flows into Medicaid reproduce all of these features of the data. The model also reproduces the magnitudes of the flows into Medicaid for married households, although it overstates the flows of widows aged 65-74. This may be due to the fact that we do not allow people to qualify for Medicaid before age 65 in the model. In the data some widows qualify for Medicaid before age 65 and thus the flow at age 65 is lower.

\subsection{Out-of-pocket medical expenses}

Figure 3 reports OOP medical expenses of households in the data and the model by marital status and social security income quintile. De Nardi et al. (2006) show that OOP medical expenses of single individuals are increasing by permanent income quintile. ${ }^{15}$ Consistent with

\footnotetext{
${ }^{15}$ De Nardi et al. (2006) use annuitized income to proxy for permanent income. Constructing annuitized income for households is subtle. So we use social security income instead. It is the largest component of
} 

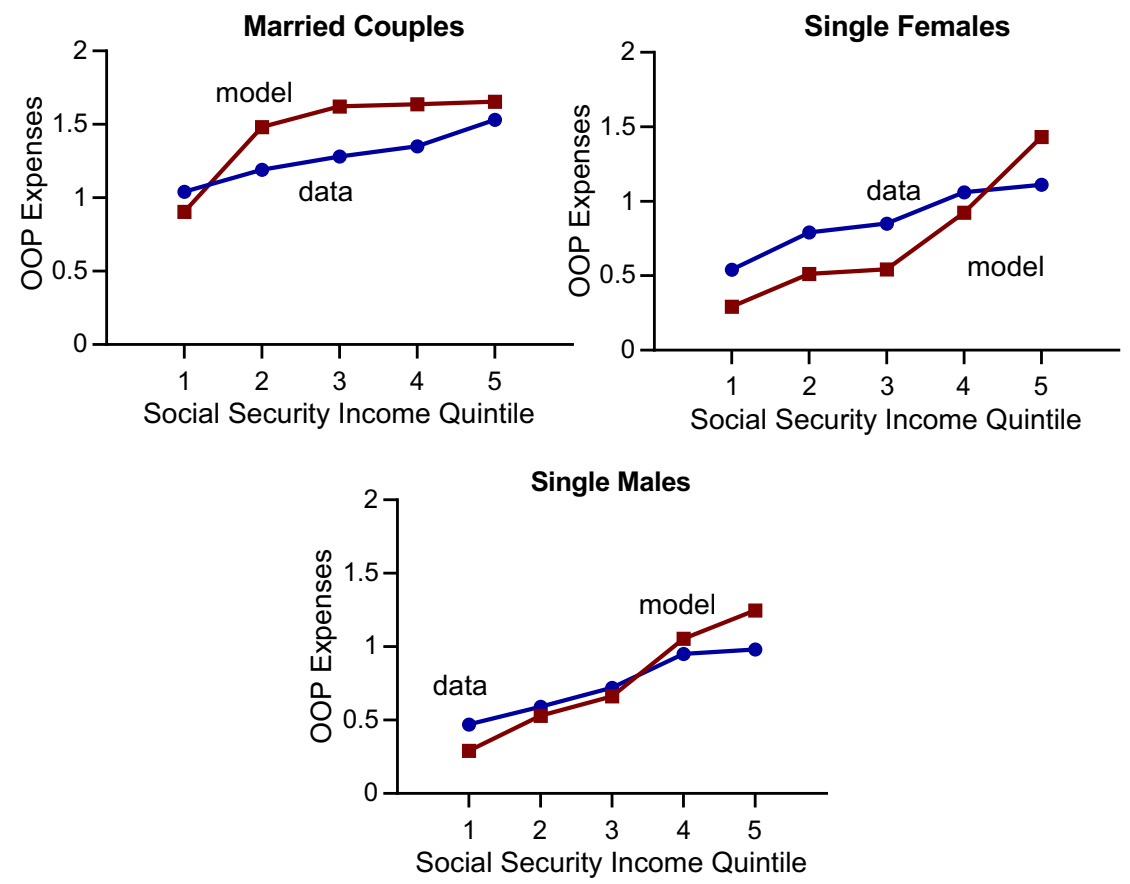

Figure 3: Out-of-pocket health expenses of married couples (top, left), single females (top, right) and single males (bottom) relative to mean OOP expenses of all households by social security income quintile in the model (red squares) and the data (blue circles).

these findings, Figure 3 shows that household's OOP expenses increase with social security income in the data. Observe that OOP expenses also increase with social security income in the model. The primary reason for this is that, as income increases, the fraction of medical expenses covered by Medicaid falls. If the increase in OOP expenses with income in the data is, at least, in part due to wealthier households purchasing more quantity or quality of care, one might expect the model to understate OOP expenses of high income households. However, the model actually overstates OOP expenses of high income widowers and widows. We believe that these gaps are due to the fact that in the model there is no medically-needy path to Medicaid. In the data, some high income household are eligible for Medicaid under this path and have reduced OOP expenses as a result. ${ }^{16}$

\subsection{Probability and Persistence of Impoverishment}

We next discuss how well the model reproduces the differentials in downward mobility discussed in Section 2. Recall that we found evidence in the data that singles face a higher probability of impoverishment as compared to married individuals and that poverty is a more

annuitized income and we can observe it at the household level in both the model and the data.

${ }^{16}$ Source: Kaiser Commission on Medicaid and the Uninsured, December 2012. 
Table 11: Conditional transitions into poverty

\begin{tabular}{|c|c|c|c|c|c|c|}
\hline \multirow[b]{2}{*}{ Cohort } & \multicolumn{3}{|c|}{ Model } & \multicolumn{3}{|c|}{ Data } \\
\hline & $65-74$ & $75-84$ & $85+$ & $65-74$ & $75-84$ & $85+$ \\
\hline \multicolumn{7}{|c|}{ Marital Status (Women) } \\
\hline married & 1.15 & 1.02 & 4.30 & 5.49 & 5.76 & 10.64 \\
\hline widow & 3.85 & 4.47 & 5.61 & 8.01 & 7.59 & 12.11 \\
\hline \multicolumn{7}{|c|}{ Marital Status (Men) } \\
\hline married & 0.77 & 1.72 & 4.30 & 6.08 & 5.93 & 5.90 \\
\hline widower & 3.14 & 3.42 & 5.61 & 10.36 & 8.05 & 8.89 \\
\hline \multicolumn{7}{|l|}{ Health Status } \\
\hline good & 2.09 & 3.77 & 4.83 & 5.06 & 5.16 & 7.76 \\
\hline bad & 2.60 & 4.65 & 5.56 & 7.94 & 8.68 & 10.78 \\
\hline \multicolumn{7}{|l|}{ Hospital } \\
\hline no hospital stay & 1.41 & 3.43 & 4.14 & 5.80 & 5.76 & 8.74 \\
\hline hospital stay & 6.06 & 9.15 & 8.27 & 6.51 & 7.00 & 9.07 \\
\hline \multicolumn{7}{|l|}{ Nursing Home } \\
\hline no NH stay & 2.13 & 3.85 & 4.65 & 5.85 & 6.05 & 8.06 \\
\hline NH stay & 9.16 & 9.05 & 7.94 & 10.94 & 11.12 & 14.73 \\
\hline
\end{tabular}

The numbers are the percentage of individuals in wealth quintiles $2-5$ who move to quintile 1 two years later conditional on their initial status. Wealth quintiles are determined from an individual wealth distribution specific to each age group. Married individuals are assigned half of the household wealth. 
Table 12: Conditional persistence of poverty

\begin{tabular}{lrrrrrr}
\hline \hline & \multicolumn{3}{c}{ Model } & \multicolumn{3}{c}{ Data } \\
\multicolumn{1}{c}{ Cohort } & $65-74$ & $75-84$ & $85+$ & $65-74$ & $75-84$ & $85+$ \\
\hline $\begin{array}{l}\text { Marital Status (Women) } \\
\text { married }\end{array}$ & 75.6 & 71.1 & 68.5 & 72.5 & 69.6 & 80.2 \\
$\quad$ widow & 94.4 & 88.5 & 78.3 & 80.0 & 75.9 & 76.1 \\
$\begin{array}{l}\text { Marital Status (Men) } \\
\text { married }\end{array}$ & 89.0 & 81.7 & 34.3 & 74.5 & 73.9 & 70.7 \\
$\quad$ widower & 99.2 & 96.5 & 100 & 75.7 & 79.0 & 73.9 \\
$\begin{array}{l}\text { Health Status } \\
\text { good }\end{array}$ & & & & & & \\
$\quad$ bad & 90.7 & 83.3 & 79.8 & 69.7 & 70.8 & 67.8 \\
$\begin{array}{l}\text { Hospital } \\
\text { no hospital stay }\end{array}$ & 92.4 & 85.7 & 79.9 & 80.9 & 79.3 & 73.1 \\
$\quad$ hospital stay & 97.8 & 80.2 & 77.2 & 75.3 & 73.1 & 71.0 \\
Nursing Home & & & & & & \\
$\quad$ no NH stay & 91.0 & 83.8 & 78.7 & 75.7 & 74.6 & 69.3 \\
$\quad$ NH stay & 99.3 & 85.9 & 85.9 & 87.9 & 86.0 & 75.6 \\
\hline \hline
\end{tabular}

The numbers are the percentage of individuals in wealth quintile 1 who are still in quintile 1 two years later conditional on their initial status. Wealth quintiles are determined from an individual wealth distribution specific to each age group. Married individuals are assigned half of the household wealth.

persistent state for singles. Poor health status, hospital stays and nursing home expenditures also increase the likelihood and the persistence of impoverishment.

Our model exhibits these properties of the data. Table 11 reports conditional transitions into poverty and Table 12 reports the persistence of impoverishment over the period of two years for the same indicators that were described in Section 2. Frequencies of impoverishment are reported as the percentage of individuals in the upper wealth quintiles (Q2 through Q5) moving to the bottom wealth quintile (Q1). The persistence of impoverishment is measured by the fraction of individuals in wealth quintile Q1 staying in the same quintile.

Inspection of both tables indicates that the model is in reasonably good accord with the data. First, observe that widows and widowers of all ages face a higher probability and a higher persistence of impoverishment compared to married individuals of the same gender. Next, consider the effects of health and medical expenses on the probability of impoverishment and its persistence. In the model, bad health is associated with a higher probability of moving to the bottom wealth quintile and a higher probability of staying there. 
One way to compare the effects of medical expenses in the model with those in the data is to interpret the highest draw of the medical expense shock in the model as a nursing home stay and the second highest draw as a hospital stay. Both events increase the likelihood and persistence of impoverishment in the model as well as in the data.

The fact that the model understates the magnitudes of the flows into poverty is not surprising. Our model is quite detailed, but it does not consider all risks faced by retirees. Divorce, remarriage, inheritances, real estate returns and stock market returns are all absent from the model. Moreover, even if we could model all of these risks, the model would still understate the wealth mobility in our data. As pointed out by Poterba, Wise and Venti (2010), there is a serious possibility that many of the bigger moves in the data are due to reporting and/or measurement errors. We have made an effort to control for these measurement problems but it is quite likely that there are some remaining spurious transitions in our data. It is consequently to be expected that the model will understate the transition percentages in the data.

\section{Welfare Analysis}

We now turn to conduct a welfare analysis of SS and means-tested SI. In order to understand the roles of these social insurance programs we report simulation results for four versions of the model. The 'no SI' economy has no social security and no means-tested SI for retirees. The 'SS only' and 'means-tested SI only' economies have only one of the programs while the 'both (U.S. economy)' version has both programs. ${ }^{17}$ The upper panel of Table 13 reports results for the baseline specification of the model and the lower panel reports results for a specification of the model with no medical expenses. ${ }^{18}$ The ratio of government purchases to GDP is held fixed at the same value in all four economies and the proportional tax coefficient in the income tax schedule is adjusted to satisfy the government budget constraint. Welfare is measured as an equivalent consumption variation - a constant percentage change in consumption of each household in every period of its life which makes the household indifferent between the 'no SI' economy and the alternative economy. We limit attention to a comparison of steady-states. In particular, we ask which economy offers higher welfare to newborn agents.

Let's start by comparing the baseline 'no SI' and 'SS only' economies. We find that a newborn would prefer to be born into the 'no SI' economy. In particular, there is a $5.11 \%$

\footnotetext{
${ }^{17}$ Formally, consumption floors for retirees in the 'no SI' economy set to $0.01 \%$ of average earnings. At this level $0.3 \%$ of retirees are on the floor.

${ }^{18}$ When medical expenses are set to zero, we also remove means-tested Medicaid benefits from the model. Other means-tested income support is still modeled.
} 
Table 13: Aggregate variables for four economies: 'baseline' and the 'no medical expense' specifications

\begin{tabular}{lcccc}
\hline \hline Economy & No SI & SS Only & $\begin{array}{c}\text { Means-tested } \\
\text { SI Only }\end{array}$ & $\begin{array}{c}\text { Both } \\
\text { (U.S. Economy) }\end{array}$ \\
\hline 'Baseline' Specification & & & & \\
Output & 1.00 & 0.81 & 0.81 & 0.74 \\
Consumption & 0.71 & 0.56 & 0.56 & 0.50 \\
Wealth & 6.94 & 3.60 & 3.81 & 2.44 \\
Working Females' Hours & 0.39 & 0.38 & 0.33 & 0.34 \\
Female Labor-Force Part. & 0.49 & 0.52 & 0.44 & 0.46 \\
Proportional Tax & -0.16 & -0.04 & -0.04 & 0.00 \\
Welfare, \% & 0.00 & -5.11 & 14.0 & 2.22 \\
\hline 'No Medical Expense' Specification & & \\
Output & 1.00 & 0.84 & 0.97 & 0.84 \\
Consumption & 0.71 & 0.58 & 0.69 & 0.58 \\
Wealth & 5.43 & 2.62 & 5.01 & 2.61 \\
Working Females' Hours & 0.35 & 0.34 & 0.34 & 0.34 \\
Female Labor-Force Part. & 0.46 & 0.47 & 0.45 & 0.46 \\
Proportional Tax & -0.09 & -0.00 & -0.08 & 0.00 \\
Welfare, \% & 0.00 & -10.3 & 1.89 & -10.0 \\
\hline \hline
\end{tabular}

Results are reported for four economies and two specifications of the model. The first column is the 'No SI' economy in which there is no social security and no means-tested welfare for retirees. The second column is the 'SS Only' economy which has only social security. The third column is the 'Means-tested SI only' economy which has only means-tested SI. The last column, 'Both (U.S. Economy)', has both programs. The 'baseline' specification includes medical expenses and the 'no medical expense' specification sets medical expenses to zero. All flows are annualized. The measure of output in this table is GNP. Welfare is measured as an equivalent consumption variation - a constant percentage change in consumption of each household in every period of its life that makes the household indifferent between the 'No SI' economy and the alternative economy. 
welfare loss of introducing SS. This is because the 'no SI' economy has more wealth and higher consumption. SS distorts the savings decision and households save less. Interestingly, average female hours worked by all women increases in the economy with SS. Underlying this response are two countervailing effects. ${ }^{19}$ First, females increase participation so that they can qualify for SS benefits. Second, a higher income tax is needed under SS to balance the government budget constraint and this acts to depress hours per working female. The participation effect is larger and average female hours worked by all women increases.

One difference between our results and the previous literature is that the welfare cost of social security is significantly smaller in our model. Hong and Ríos (2007), for instance, report about a $12 \%$ welfare gain from removing SS. Their model is similar to ours in some respects. They consider a small open economy and they model changes in family status. An important distinction between our analysis and Hong and Ríos (2007) is that we model medical expenses and their associated risks. The lower panel of Table 13 reports results for our model when medical expenses are set to zero. Observe that the welfare loss of introducing SS more than doubles, increasing to $10.25 \%$ which is about the same size as Hong and Ríos (2007). ${ }^{20}$ The reason for this is that agents face a range of risks in our baseline model that are absent when medical expenses are set to zero. In the baseline specification, medical expenses are increasing with age and SS is partially insuring these risks. Some intuition for this result can be found in Conesa and Krueger (1999) who show that the value of SS is higher when markets are incomplete and agents face uninsured idiosyncratic risk.

Moreover, if we vary some of our modeling assumptions the welfare costs of SS become even smaller and, in some cases, even negative in our baseline specification. Two ways to reverse the relative ranking of these two economies are to assume that death is not foreseen or that the economy is closed. In the case where death is not foreseen, the annuity value of SS benefits increases as SS allows individuals to reduce the size of their accidental bequests. In the case of a closed economy, introducing SS leads to an increase in the interest rate and this partially offsets the savings distortion created by a pay-as-you go pension system. ${ }^{21,22}$

Consider next the baseline specification with means-tested SI only. Welfare is dramati-

\footnotetext{
${ }^{19}$ Recall that we are assuming that male labor supply is inelastic.

${ }^{20}$ Although the welfare results are similar in this scenario there are some other differences. In particular, consumption declines by $18 \%$ in our economy with no medical expenses and by only $7 \%$ in their economy when SS is introduced. There are two reasons for this difference. First, wealth changes more in our economy because there is no bequest motive. Second, unlike in Hong and Ríos (2007), individuals in our economy can foresee their death. Thus they consume all their remaining wealth in the last year of their life. When SS is introduced, the decrease in savings for survival risk results in a sharp, $62 \%$, decline in end-of-life consumption.

${ }^{21}$ Simulations that demonstrate these points are available from the authors upon request.

${ }^{22} \mathrm{~A}$ third way to reverse the welfare ranking in these two economies is to lower the consumption floors. We discuss this point in more detail below when we compare our results with Feldstein (1987).
} 
cally higher (14\%) in this economy than in the 'no SI' economy. To understand this finding one must balance the negative incentive effects of means-tested SI against its insurance benefits. The negative incentive effects can be readily discerned in macroeconomic aggregates. Introducing means-tested SI produces similar reductions in consumption and output as introducing SS. In addition, both female participation and average hours of working women decline. One of the negative incentive effects is due to higher taxes. The introduction of means-tested SI requires government outlays amounting to $2.52 \%$ of GNP. This results in higher income taxes and lower economic activity. The second negative incentive effect has been emphasized by Feldstein (1987) and Hubbard et al. (1995). When means-tested SI is available to retirees, poorer households will choose not to save for retirement. Instead they consume all of their earnings while working and then roll directly onto means-tested SI at retirement. In the 'means-tested SI only' economy this effect is very large and $21 \%$ of all individuals start receiving means-tested benefits at age 65 .

We find that the large magnitude of this second incentive effect is due to the presence of old age medical expenses and their associated risks. When we set medical expenses to zero, the fraction of households who start receiving means-tested benefits at age 65 falls to $5 \%$. To understand this finding, note that there is more risk during retirement when medical expenses are modeled. With means-tested SI agents must first use their own resources to cover these expenses. What this means is that in some states of nature savings are subject to implicit taxes of up to $100 \%$. Poorer households are more likely to experience a high implicit tax during retirement and thus have a lower expected return on savings. Their optimal response is to not save for retirement.

In spite of these negative incentive effects the 'means-tested SI only' economy delivers the highest welfare of all four economies and by a substantial margin. The single biggest reason for this large difference in welfare is that this form of social insurance is an effective way to insure against old age medical expense related risks. In contrast to SS benefits, means-tested SI transfers pay out in situations where medical expenses are large and thus the need for insurance is largest. Results in the lower panel illustrate this point. Notice that newborn still like the 'means-tested SI only' economy best when medical expenses are zero. However, the welfare gap between this economy and the economy with no SI is substantially smaller and for some households such as those who are college educated the gap is close to zero.

Our results for the 'no medical expense' specification are related to research on Australia by Tran and Woodland (2012). All public pensions are means-tested in Australia. Tran and Woodland (2012) assess the welfare benefits of this system in a small open economy, OLG model with earnings and survival risks. They find that the negative incentive effects of this public pension system are so large that newborn agents prefer no public pension. 
They go on to show that this result is sensitive. Modifying the rate at which benefits taper off can produce welfare gains as compared to no program. Similarly, in our 'no medical expense' specification, one can come up with variants of the calibration that would overturn our relative ranking of the 'no SI' and the 'means-tested SI only' economies. One way to do this would be to raise the consumption floors guaranteed by means-tested SI. However, the welfare benefits of means-tested SI are much larger once medical expenses and their associated risks are taken into account.

More generally, our baseline result that welfare is much higher in the 'means-tested SI only' economy as compared to any other economy is very robust to some of the other details of the model. As long as medical expenses and associated risks are present, changes to the model, including removing anticipated death, closing the economy, or holding taxes fixed as is done in partial equilibrium analyses, do not overturn our result. Utility of newborn is highest in the 'means-tested SI only' economy regardless of whether these changes in the model are made individually or jointly. ${ }^{23}$

So far we have considered each program in isolation. We now turn to discuss the interactions when both programs are present as is the case in the U.S. We have seen that newborn like the 'means-tested SI only' economy best in spite of the fact that there are large distortions on incentives. Adding SS to this economy alters these incentives. Recall that for some households the availability of means-tested income and health expenditure support at retirement has a particularly strong influence on their savings decision. They choose to consume all of their income while working and then to rely on means-tested SI at retirement. Introducing social security decreases the fraction of agents who pursue this strategy. These effects are illustrated in Figure 4. This figure displays the decline in Medicaid take-up rates by age for each male permanent earnings quintile when social security is introduced into the 'means-tested SI only' economy. ${ }^{24}$ The left panel shows results for the 'baseline' specification and the right panel displays the same information for the 'no medical expense' specification.

In the baseline specification introducing social security has a very pronounced effect on take-up rates. The fraction of households who choose to roll into SS at retirement falls by $15 \%$ for permanent earnings quintile 1, $15 \%$ for quintile 2 and $18 \%$ for quintile 3 . Interestingly, there is no increase in take-up rates at retirement for those in quintiles 4 and 5. Note also that the pattern of the additional Medicaid enrollment varies quite distinctly by age and quintile. For those in quintiles 1 and 2, the decline in enrollment plummets early and then increases with age. In quintile 3, the fall in enrollment continues until age 83. And for the

\footnotetext{
${ }^{23}$ Simulations that demonstrate this point are available from the authors upon request.

${ }^{24}$ We wish to emphasize that male permanent earnings are distinct from household wealth or household earnings. We use male permanent earnings because they are exogenous. This makes it possible to compare the same individuals across economies.
} 

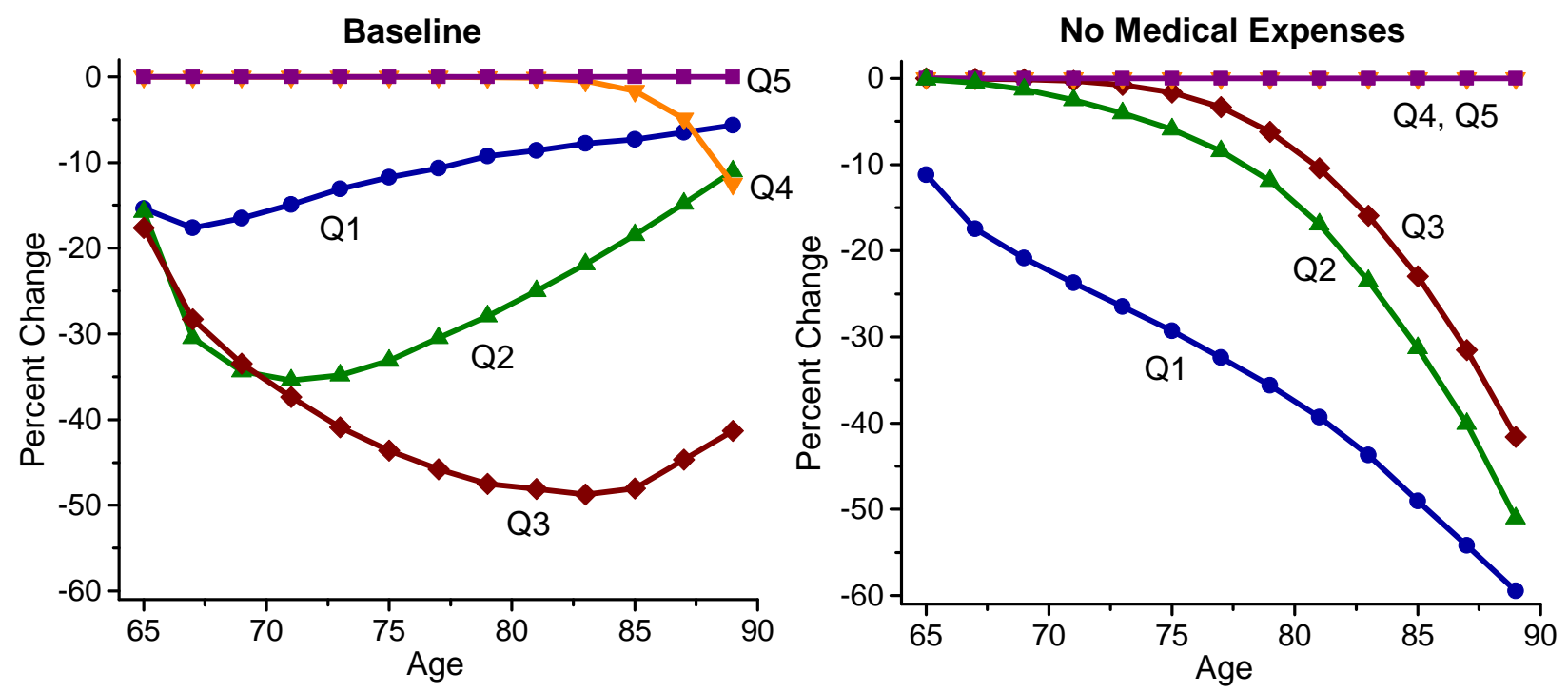

Figure 4: The percentage decrease in means-tested SI take-up rates of retirees when social security is introduced into the 'means-tested SI only' economy. The change in the take-up rates is shown by age and male permanent earnings quintile. The left panel is the baseline specification and the right panel is the 'no medical expense' specification. The percentage decrease is calculated by subtracting the take-up rates in the economy with means-tested SI only from those in the economy with both means-tested SI and SS.

top two quintiles take-up rates are zero until very late in life.

The reason why introducing SS has such a dramatic impact on means-tested SI take-up rates is because it ameliorates the negative saving effect of means-tested SI described above. SS forces some households to save for retirement who would choose not to save otherwise. This forced savings increases the expected return from private savings and some households alter their strategy and choose to save on their own as well.

The effect of introducing SS on means-tested take-up rates is most pronounced when medical expenses are present. This can be seen by comparing the left-hand and righthand panels of Figure 4. In the economy without medical expenses, when social security is introduced, only $10 \%$ of those in the first quintile choose not to save but roll into meanstested SI at retirement. Households in all other quintiles choose to save while working in order to smooth consumption over their life-cycle when social security is introduced. Another difference between the two panels is that in the right panel take-up rates decrease monotonically with age for those in quintiles 1-3. It is clear from this figure, that when medical risks are absent, the primary role played by means-tested income support is insurance against survival risk.

Overall, introducing SS reduces means-tested SI take-up rates from $34 \%$ to $13 \%$. As a result, government expenditures on means-tested SI for retirees fall from $2.52 \%$ of GNP to 
Table 14: Welfare effects of introducing social security into the 'means-tested SI only' economy and the 'no SI' economy by household type

\begin{tabular}{lcccc}
\hline \hline Economy & \multicolumn{2}{c}{ Means-tested SI only } & \multicolumn{2}{c}{ No SI } \\
Income Taxes & Adjusted & Fixed & Adjusted & Fixed \\
\hline Average & -11.8 & -9.14 & -5.11 & -1.88 \\
By male permanent earnings: & & & & \\
$\quad$ quintile 1 & -11.4 & -9.66 & -2.54 & -0.68 \\
quintile 2 & -11.9 & -9.50 & -4.61 & -1.82 \\
quintile 3 & -11.9 & -9.20 & -5.61 & -2.22 \\
quintile 4 & -12.0 & -8.91 & -6.42 & -2.50 \\
quintile 5 & -11.9 & -8.11 & -8.34 & -2.92 \\
By household education type & $($ female, male): & & \\
high school, high school & -11.8 & -9.49 & -4.31 & -1.72 \\
high school, college & -11.1 & -7.69 & -6.68 & -1.96 \\
college, high school & -12.8 & -9.68 & -7.01 & -2.68 \\
college, college & -12.2 & -8.16 & -8.95 & -2.69 \\
\hline \hline
\end{tabular}

Columns are the percentage change in welfare of introducing SS into the 'means-tested SI only' and the 'no SI' economies. The first and third columns show the welfare change when income taxes adjust to balance the government budget constraint. The second and fourth columns show the welfare change when income taxes remain fixed at their value before SS is introduced. Welfare changes are measured as equivalent consumption variations - the constant percentage change in consumption of each household in every period of its life that makes the household indifferent between the reference economy and the reference economy with SS.

0.80\% of GNP. Despite this, taxes go up in the economy with both programs. The negative effect of SS on private savings that we discussed above are still significant and wealth is lower in the economy with both programs as compared to the economy with means-test SI only. Despite the large fiscal benefits we have described welfare of a newborn falls when this program is introduced. Rich households like lower means-tested take-up rates because they lower government outlays but the poor do not. Effectively forcing the poor to save lowers their utility. These factors in conjunction with the low effective return of SS contributions act to lower average welfare of newborn by $11.8 \%$.

So far we have limited attention to average welfare of a newborn. Column one of Table 14 reports the change in welfare going from the 'means-tested SI only' economy to the economy with both programs for different types of households. A comparison of welfare in these two economies is of interest because the 'means-tested SI only' economy produces the highest average welfare and the economy with both programs is our baseline model for the U.S. 
Welfare changes are reported by education status of the female and male members of the household. For purposes of comparison, we also report welfare organized by male permanent earnings quintile. The results are very strong: welfare of all types of households is lower in the economy with both programs as compared to the economy with means-tested SI only.

Table 14 has several other noteworthy properties that can be seen by considering the second column, which holds income taxes fixed at their levels in the 'means-tested SI only' economy. This corresponds to the type of situation considered in partial equilibrium studies. Observe that holding taxes fixed understates the total welfare loss of introducing SS. As we noted above, introducing SS has two fiscal effects: it reduces means-tested SI take-up rates; and it distorts the saving decision of more affluent households. This latter effect is dominant and taxes go up when they are allowed to adjust and welfare of all types falls.

The treatment of taxes also affects the pattern of welfare losses. When taxes are held fixed, the welfare losses increase with permanent earnings, but when taxes are allowed to adjust, this pattern is reversed. With taxes fixed the poor are particularly unhappy about the introduction of SS. This program prevents them from running down their wealth and reduces their ability to qualify for means-tested SI when retired. The rich, in contrast, dislike SS less since they do not have to pay for it. Once taxes adjust though, the rich are particularly, unhappy. They are subject to a disproportionate share of the tax burden due to the tapering in U.S. SS benefit formulas (replacement rates fall as indexed earnings increase, as reported in Section 8.3.6).

Finally, note that households with college educated males dislike SS less than households with high-school educated males. The reason for this asymmetry is that SS provides spousal and survivor benefits that are particularly attractive to households with college educated males.

The final two columns of Table 14 report results that are designed to understand welfare of the poor when SS is introduced into an economy with very small means-tested SI. Feldstein (1987) has previously argued that the poor will prefer SS to means-tested SI if means-tested SI support levels are sufficiently low. Moreover, he asserts that the benefits for the poor of introducing SS could be so large as to dominate the welfare losses for other households. We evaluate these claims by considering the welfare effects of moving from the 'no SI' economy to the economy with SS only. Recall that in our 'no SI' economy consumption floors of retirees are set at $0.1 \%$ of average earnings or about $\$ 48$ per year using year 2000 prices. Introducing SS into the 'no SI' economy thus provides us with a way to see whether poor benefit from SS when consumption floors are set to a very low level. Table 14 shows that regardless of whether taxes are held fixed or allowed to adjust, quintile 1 households prefer to be born into the economy with no SS. Even this very low setting of the consumption floor is 
Table 15: Welfare and fiscal effects of changes in the means-tested SI consumption floor

\begin{tabular}{lcccc}
\hline \hline $\begin{array}{l}\text { Means-tested SI floors } \\
\text { Tax Adjusting }\end{array}$ & No change & $\begin{array}{c}30 \% \text { up } \\
\text { Income }\end{array}$ & $\begin{array}{c}30 \% \text { up } \\
\text { Payroll }\end{array}$ & $\begin{array}{c}30 \% \text { down } \\
\text { Income }\end{array}$ \\
\hline $\begin{array}{l}\text { Welfare } \\
\quad \text { Average }\end{array}$ & 0.0 & -0.44 & 0.54 & 0.04 \\
$\quad$ By household education type & (female, male): & & \\
$\quad$ high school, high school & 0.0 & -0.24 & 0.62 & -0.13 \\
$\quad$ high school, college & 0.0 & -0.91 & 0.35 & 0.45 \\
$\quad$ college, high school & 0.0 & -0.69 & 0.48 & 0.28 \\
$\quad$ college, college & 0.0 & -1.20 & 0.29 & 0.65 \\
Means-tested SI & & & & \\
$\quad$ take-up rates & 12.9 & 24.1 & 23.7 & 6.0 \\
$\quad$ government outlays, \% GNP & 0.80 & 1.57 & 1.53 & 0.33 \\
\hline \hline
\end{tabular}

The first column is the 'both (U.S. economy)' version under the baseline specification. The second column shows the welfare and fiscal effects of increasing the means-tested SI floor by $30 \%$ financed by an an increase in income taxes. The third column shows the effect if the increase is financed by payroll taxes instead. The final column shows the effect if the floor is instead reduced by $30 \%$ and income taxes are adjusted. Welfare is measured as an equivalent consumption variation a constant percentage change in consumption of each household in every period of its life which makes the household indifferent between the 'both (U.S. economy)' version and the alternative economy with a different consumption floor.

too large to be consistent with Feldstein's assertions. We have experimented with even lower consumption floors and found that if the consumption floor is set at $\$ 4.8$ instead, welfare of the poor and average welfare of the newborn are both higher when SS is introduced to the 'no SI' economy. Medical expense and associated risks play an essential role in confirming Feldstein's assertions. In particular, if medical expenses are zero, average utility of a newborn is higher in the economy with no SS. Even though it is possible to produce examples where means-tested SI is so low that agents prefer SS, these cases are not relevant for the U.S. As we have shown, as long as means-tested SI remains close to levels currently available, all newborn strongly prefer the economy with means-tested SI only over all other economies we have considered.

\subsection{Reforming Social Insurance for Retirees}

We have found that the long-run welfare benefits of shutting down SS and moving to a single means-tested SI system for retirees are very large. It is clear though that the costs of compensating retirees who loose SS benefits could offset some of these long-run welfare 
gains. Assessing whether the U.S. should transition to a means-tested only SI system is beyond the scope of this paper. Instead we focus on reforms of means-tested SI holding SS fixed at its current level. We will provide an example where all types of newborn benefit from increasing the current scale of means-tested SI for retirees in the U.S. In this example, the costs of transition are not an issue. Current retirees benefit immediately from enhanced retirement benefits and working households enjoy the same enhanced benefits when they retire.

The central factor that determines the signs of the welfare effects of increasing meanstested SI is how these additional benefits are financed. We find that welfare of all newborn increases if the expansion of means-tested SI is financed with a payroll tax, but that all newborn prefer the status quo if the income tax is used instead. These points are illustrated in columns two and three of Table 15, which reports welfare changes associated with moving from the economy with both programs to an economy in which consumption floors for retirees are $30 \%$ higher. Results are reported for average utility of a newborn and utility by educational type. When means-tested SI expansion is financed by a payroll tax, average welfare of a newborn increases by $0.54 \%$. More importantly, all education types are better off. Since educational status is the only source of initial heterogeneity, these results imply that all newborn would prefer to be born into the economy with higher means-tested benefits and higher payroll taxes even after they know their educational type. In contrast, if the expansion is financed by a higher income tax, average welfare of a newborn declines by $0.44 \%$ and all newborn are worse off.

The reasons for this difference are that the payroll tax only applies to labor income and is proportional, while the income tax applies to both labor and capital income and is progressive. As a result an expansion of means-tested SI financed by the income tax leads to a larger reduction in savings and a greater increase in SI take-up rates.

Our finding that households don't want to increase means-tested SI if it is financed with a higher income tax raises the question of whether they would prefer a smaller means-tested SI program and lower income taxes. The final column of Table 15 shows that average utility is in fact marginally (0.04\%) higher when consumption floors are reduced by $30 \%$. However, there is a disagreement among newborn. Households with two high school educated members are worse off. However, this loss is smaller than the combined gain of other types of newborn.

\subsection{Robustness}

Before concluding we briefly discuss the robustness of our results to several simplifying assumptions we have made. Probably the most important question concerning our assumptions 
pertains to medical expenses and their associated risks. We have found that these risks play a central role in our welfare analysis and the question that arises is how robust are our conclusions to our assumptions about the availability of alternative forms of insurance against these risks.

First, our conclusions are premised on a model that abstracts from private insurance markets. It is doubtless the case that if these markets were modeled and no SI was available demand for products such as life insurance and long-term care insurance would increase. However, it is our view that the increase in take-up rates in these markets would be small. Hendren (2013) finds that rejection rates in these insurance markets are high. He argues that an important reason for this is asymmetric information. Namely, individuals have superior information about their health status as compared to issuers and this information is significant in the sense that it can have a very large impact on payouts and thus pricing. Adverse selection limits the functioning of these markets in several ways. Insurers deny coverage to individuals who have observable characteristics that predispose them to these risks. Other individuals who know they have low risk will choose not to purchase insurance. Moreover, some poor individuals will not be able to afford private insurance even if they want it. Absent a government mandate or other types of regulation it is likely that many individuals will end up old, sick alone, poor and uninsured.

Second, Medicare also provides insurance against old-age medical risks. We model the component of the payroll tax that is used to finance Medicare and retirees OOP medical expenses are net of Medicare benefits. However, we are not able to explicitly link Medicare tax contributions to Medicare benefits because our HRS data does not include pre-Medicare medical expenses. Consequently, it is difficult to consider experiments that assess the welfare benefits of Medicare. Still, our current results do shed some light on how agents would assess a change in the scale of Medicare. Medicare is a universal pay-as-you-go public healthcare program and has the same incentive effects on savings as SS. We thus conjecture that, if the scale of Medicare were reduced in our model where medical expenditures are exogenous, newborn households would also experience welfare gains.

A final type of insurance of medical risks for retirees is Medigap, a government regulated private insurance market that covers copayments, deductibles and other OOP expenses for Medicare insured risks. Medigap provides no coverage for long-term care expenses which is the biggest source of medical risk for retirees (see Kopecky and Koreshkova (2007)).

We have found that the welfare benefits of means-tested SI are large. Are we overstating them? If anything, our estimates may be too conservative because we have assumed that medical expenses are not growing. Since 1980 health-expenditures as a fraction of GDP 
have doubled. ${ }^{25}$ If we were to model this observation the welfare benefits of means-tested SI would be even larger.

In this paper we have focused on the welfare effects of changes in the scale of SS and means-tested SI. We have not considered alternative arrangements that might be better. The large welfare gains of removing SS in our model are driven by the fact that the effective return on SS contributions is very low. This has led others such as Prescott and McGrattan (2012) to propose defined contribution public pension plans instead. In our model, poorer households will not like this program because it forces them to save more, reducing their ability to rely on means-tested SI during retirement. However, wealthier households will like this program. They plan to save anyway and the return on their defined contributions will be close to the return on their private savings. Moreover, by forcing the poor to save, the program decreases government outlays for means-tested SI and thus taxes to finance them. Given the opposing impact of such a program on the welfare of the rich versus the poor, it is unclear whether average welfare would increase of fall if this type of pension program were implemented. However, work by Golosov and Tsyvinski (2006) suggests that even if such a program was offered that there would still be a Pareto enhancing role for means-tested SI.

\section{Conclusion}

One of the central objectives of public policy is to provide for those who are sick and do not have the financial means to cover their medical and living expenses. For the aged, this risk is significant and can be compounded by a spousal death event leaving the retiree not only sick and alone but also poor. We have shown that modeling these factors has a very large impact on the relative welfare benefits of two social insurance (SI) programs that help retirees cope with these risks: means-tested SI and Social Security (SS). We find the following. First, given the choice of either no SI programs, a SS program only or a meanstested SI program only, all newborn individuals strongly prefer the means-tested SI program only to no SI programs and all newborn prefer no SI programs at all to having only a SS program. Second, when means-tested SI is available, there is a large welfare loss associated with the additional presence of SS. In other words, Friedman's suggestion to get rid of SS is good policy in our setting: means-tested SI is enough. Third, given the presence of SS, the current scale of means-tested SI for retirees is about right.

\footnotetext{
${ }^{25}$ See OECD Health Data.
} 


\section{Appendix}

\subsection{Our HRS sample}

The principal data set used in this paper the 1995-2010 waves of HRS and AHEAD and includes retired individuals aged 65 and above who are single or married to retired spouses. Our sample is essentially the same as that of Kopecky and Koreshkova (2007) and we refer the interested reader to that paper for more specifics on the construction of the sample. We define healthy individuals to be those who self-report their health status to be excellent, very good or good.

\subsubsection{Wealth Transitions}

We use the wealth variable (ATOTN) which is reported at the household level in the HRS. This wealth measure is the sum of the value of owned real estate (excluding primary residence), vehicles, businesses, IRA/Keogh accounts, stocks, bonds, checking/savings accounts, CDs, treasury bills and "other savings and assets," less any debt reported. To carry out an analysis of individuals, wealth is divided by two for married couples (and is left as is for single people). Additionally, irregular patterns in the dataset are fixed to eliminate spurious wealth transitions. For example, if a person has wealth $>0$ in period 1, wealth $=0$ in period 2 , and wealth $>0$ in period 3 , the wealth in period 2 is replaced by the average of the wealth in period 1 and period 3. These patterns are present in less than 1 percent of the total number of observations. Finally, wealth is censored at $-\$ 500$ (if $-\$ 500<$ wealth $<0$ ) and at $\$ 500$ (if $0 \leq$ wealth $<\$ 500$ ) to avoid problems of dividing by 0 or very small numbers when calculating percent changes in wealth from period to period.

Wealth is reported in real terms. This is accomplished by deflating reported nominal wealth using the CPI.

For the unconditional wealth transitions, we omit most imputations of wealth performed by RAND. In particular, we only include observations where there is no imputation or wealth lies in a reported range.

For the conditional wealth transitions, the resulting samples are too small if we omit the wealth imputations performed by RAND so we include all of their imputed wealth data. Their imputations of wealth only use a households current characteristics. As a result, we are concerned that some of these imputations create spurious wealth transitions. These effects are partially controlled for by the interpolation scheme we described above. To further control for these effects, we trim the top and bottom $1 \%$ of wealth transitions in each two year interval. The omitted observations do not appear to be clustered in any systematic way. 


\subsection{Model Objects}

\subsubsection{Model Survival Rates}

The survival rate from $j-1$ to age $j$ for each household type and health status $(\mathbf{h}, d)$ is given by $\lambda_{j}(\mathbf{h}, d)$ and has the following laws of motion:

$$
\lambda_{j}\left(h^{m}=g, h^{f}=g, 0\right)=1, \quad \text { for } \quad j=1,2,3, \ldots R
$$

$$
\begin{aligned}
\lambda_{j}\left(h^{m}=g,\right. & \left.h^{f}=g, 0\right)= \\
& \frac{1}{1+n}\left[\lambda_{j-1}\left(h^{m}=g, h^{f}=g, 0\right) \pi_{j}^{m}(g, 0) \pi_{j}^{f}(g, 0) \nu_{j}^{m}(g, 0) \nu_{j}^{f}(g, 0)\right. \\
& +\lambda_{j-1}\left(h^{m}=b, h^{f}=g, 0\right) \pi_{j}^{m}(h=b, 0) \pi_{j}^{f}(g, 0) \nu_{j}^{m}(b, 0) \nu_{j}^{f}(g, 0) \\
& +\lambda_{j-1}\left(h^{m}=g, h^{f}=b, 0\right) \pi_{j}^{m}(h=g, 0) \pi_{j}^{f}(b, 0) \nu_{j}^{m}(g, 0) \nu_{j}^{f}(b, 0) \\
& \left.+\lambda_{j-1}\left(h^{m}=b, h^{f}=b, 0\right) \pi_{j}^{m}(h=b, 0) \pi_{j}^{f}(b, 0) \nu_{j}^{m}(b, 0) \nu_{j}^{f}(b, 0)\right]
\end{aligned}
$$

$$
\begin{aligned}
\lambda_{j}\left(h^{m}=b,\right. & \left.h^{f}=g, 0\right)= \\
& \frac{1}{1+n}\left[\lambda_{j-1}\left(h^{m}=g, h^{f}=g, 0\right) \pi_{j}^{m}(g, 0) \pi_{j}^{f}(g, 0)\left(1-\nu_{j}^{m}(g, 0)\right) \nu_{j}^{f}(g, 0)\right. \\
& +\lambda_{j-1}\left(h^{m}=b, h^{f}=g, 0\right) \pi_{j}^{m}(b, 0) \pi_{j}^{f}(g, 0)\left(1-\nu_{j}^{m}(b, 0)\right) \nu_{j}^{f}(g, 0) \\
& +\lambda_{j-1}\left(h^{m}=g, h^{f}=b, 0\right) \pi_{j}^{m}(g, 0) \pi_{j}^{f}(b, 0)\left(1-\nu_{j}^{m}(g, 0)\right) \nu_{j}^{f}(b, 0) \\
& \left.+\lambda_{j-1}\left(h^{m}=b, h^{f}=b, 0\right) \pi_{j}^{m}(b, 0) \pi_{j}^{f}(b, 0)\left(1-\nu_{j}^{m}(b, 0)\right) \nu_{j}^{f}(b, 0)\right]
\end{aligned}
$$

$$
\begin{aligned}
\lambda_{j}\left(h^{m}=g,\right. & \left.h^{f}=b, 0\right)= \\
& \frac{1}{1+n}\left[\lambda_{j-1}\left(h^{m}=g, h^{f}=g, 0\right) \pi_{j}^{m}(g, 0) \pi_{j}^{f}(g, 0) \nu_{j}^{m}(g, 0)\left(1-\nu_{j}^{f}(g, 0)\right)\right. \\
& +\lambda_{j-1}\left(h^{m}=b, h^{f}=g, 0\right) \pi_{j}^{m}(b, 0) \pi_{j}^{f}(g, 0) \nu_{j}^{m}(b, 0)\left(1-\nu_{j}^{f}(g, 0)\right) \\
& +\lambda_{j-1}\left(h^{m}=g, h^{f}=b, 0\right) \pi_{j}^{m}(g, 0) \pi_{j}^{f}(b, 0) \nu_{j}^{m}(g, 0)\left(1-\nu_{j}^{f}(b, 0)\right) \\
& \left.+\lambda_{j-1}\left(h^{m}=b, h^{f}=b, 0\right) \pi_{j}^{m}(b, 0) \pi_{j}^{f}(b, 0) \nu_{j}^{m}(b, 0)\left(1-\nu_{j}^{f}(b, 0)\right)\right]
\end{aligned}
$$




$$
\begin{aligned}
& \lambda_{j}\left(h^{m}=b, h^{f}=b, 0\right)= \\
& \frac{1}{1+n}\left[\lambda_{j-1}\left(h^{m}=g, h^{f}=g, 0\right) \pi_{j}^{m}(g, 0) \pi_{j}^{f}(g, 0)\left(1-\nu_{j}^{m}(g, 0)\right)\left(1-\nu_{j}^{f}(g, 0)\right)\right. \\
& +\lambda_{j-1}\left(h^{m}=b, h^{f}=g, 0\right) \pi_{j}^{m}(b, 0) \pi_{j}^{f}(g, 0)\left(1-\nu_{j}^{m}(b, 0)\right)\left(1-\nu_{j}^{f}(g, 0)\right) \\
& +\lambda_{j-1}\left(h^{m}=g, h^{f}=b, 0\right) \pi_{j}^{m}(g, 0) \pi_{j}^{f}(b, 0)\left(1-\nu_{j}^{m}(g, 0)\right)\left(1-\nu_{j}^{f}(b, 0)\right) \\
& \left.+\lambda_{j-1}\left(h^{m}=b, h^{f}=b, 0\right) \pi_{j}^{m}(b, 0) \pi_{j}^{f}(b, 0)\left(1-\nu_{j}^{m}(b, 0)\right)\left(1-\nu_{j}^{f}(b, 0)\right)\right] \\
& \lambda_{j}\left(h^{f}=b, 1\right)= \\
& \frac{1}{1+n}\left[\lambda_{j-1}\left(h^{m}=g, h^{f}=g, 0\right)\left(1-\pi_{j}^{m}(g, 0)\right) \pi_{j}^{f}(g, 0)\left(1-\nu_{j}^{f}(g, 0)\right)\right. \\
& +\lambda_{j-1}\left(h^{m}=b, h^{f}=g, 0\right)\left(1-\pi_{j}^{m}(b, 0)\right) \pi_{j}^{f}(g, 0)\left(1-\nu_{j}^{f}(g, 0)\right) \\
& +\lambda_{j-1}\left(h^{m}=g, h^{f}=b, 0\right)\left(1-\pi_{j}^{m}(g, 0)\right) \pi_{j}^{f}(b, 0)\left(1-\nu_{j}^{f}(b, 0)\right) \\
& +\lambda_{j-1}\left(h^{m}=b, h^{f}=b, 0\right)\left(1-\pi_{j}^{m}(b, 0)\right) \pi_{j}^{f}(b, 0)\left(1-\nu_{j}^{f}(b, 0)\right) \\
& +\lambda_{j-1}\left(h^{f}=b, 1\right) \pi_{j}^{f}(b, 0)\left(1-\nu_{j}^{f}(b, 0)\right) \\
& \left.+\lambda_{j-1}\left(h^{f}=g, 1\right) \pi_{j}^{f}(g, 0)\left(1-\nu_{j}^{f}(g, 0)\right)\right] \\
& \lambda_{j}\left(h^{f}=g, 1\right)= \\
& \frac{1}{1+n}\left[\lambda_{j-1}\left(h^{m}=g, h^{f}=g, 0\right)\left(1-\pi_{j}^{m}(g, 0)\right) \pi_{j}^{f}(g, 0) \nu_{j}^{f}(g, 0)\right. \\
& +\lambda_{j-1}\left(h^{m}=b, h^{f}=g, 0\right)\left(1-\pi_{j}^{m}(b, 0)\right) \pi_{j}^{f}(g, 0) \nu_{j}^{f}(g, 0) \\
& +\lambda_{j-1}\left(h^{m}=g, h^{f}=b, 0\right)\left(1-\pi_{j}^{m}(g, 0)\right) \pi_{j}^{f}(b, 0) \nu_{j}^{f}(b, 0) \\
& +\lambda_{j-1}\left(h^{m}=b, h^{f}=b, 0\right)\left(1-\pi_{j}^{m}(b, 0)\right) \pi_{j}^{f}(b, 0) \nu_{j}^{f}(b, 0) \\
& +\lambda_{j-1}\left(h^{f}=b, 1\right) \pi_{j}^{f}(b, 0) \nu_{j}^{f}(b, 0) \\
& \left.+\lambda_{j-1}\left(h^{f}=g, 1\right) \pi_{j}^{f}(g, 0) \nu_{j}^{f}(g, 0)\right]
\end{aligned}
$$




$$
\begin{aligned}
\lambda_{j}\left(h^{m}=b, 2\right)= & \\
& \frac{1}{1+n}\left[\lambda_{j-1}\left(h^{m}=g, h^{f}=g, 0\right)\left(1-\pi_{j}^{f}(g, 0)\right) \pi_{j}^{m}(g, 0)\left(1-\nu_{j}^{m}(g, 0)\right)\right. \\
& +\lambda_{j-1}\left(h^{m}=b, h^{f}=g, 0\right)\left(1-\pi_{j}^{f}(g, 0)\right) \pi_{j}^{m}(b, 0)\left(1-\nu_{j}^{m}(b, 0)\right) \\
& +\lambda_{j-1}\left(h^{m}=g, h^{f}=b, 0\right)\left(1-\pi_{j}^{f}(b, 0)\right) \pi_{j}^{m}(g, 0)\left(1-\nu_{j}^{m}(g, 0)\right) \\
& +\lambda_{j-1}\left(h^{m}=b, h^{f}=b, 0\right)\left(1-\pi_{j}^{f}(b, 0)\right) \pi_{j}^{m}(b, 0)\left(1-\nu_{j}^{m}(b, 0)\right) \\
+ & \lambda_{j-1}\left(h^{m}=b, 2\right) \pi_{j}^{m}(b, 0)\left(1-\nu_{j}^{m}(b, 0)\right) \\
+ & \left.\lambda_{j-1}\left(h^{m}=g, 2\right) \pi_{j}^{m}(g, 0)\left(1-\nu_{j}^{m}(g, 0)\right)\right] \\
& \\
& \quad \frac{1}{1+n}\left[\lambda_{j-1}\left(h^{m}=g, h^{f}=g, 0\right)\left(1-\pi_{j}^{f}(g, 0)\right) \pi_{j}^{m}(g, 0) \nu_{j}^{m}(g, 0)\right. \\
& +\lambda_{j-1}\left(h^{m}=b, h^{f}=g, 0\right)\left(1-\pi_{j}^{f}(g, 0)\right) \pi_{j}^{m}(b, 0) \nu_{j}^{m}(b, 0) \\
& +\lambda_{j-1}\left(h^{m}=g, h^{f}=b, 0\right)\left(1-\pi_{j}^{f}(b, 0)\right) \pi_{j}^{m}(b, 0) \nu_{j}^{m}(g, 0) \\
& +\lambda_{j-1}\left(h^{m}=b, h^{f}=b, 0\right)\left(1-\pi_{j}^{f}(b, 0)\right) \pi_{j}^{m}(b, 0) \nu_{j}^{m}(b, 0) \\
& +\lambda_{j-1}\left(h^{m}=b, 2\right) \pi_{j}^{m}(b, 0) \nu_{j}^{m}(b, 0) \\
& \left.+\lambda_{j-1}\left(h^{m}=g, 2\right) \pi_{j}^{m}(g, 0) \nu_{j}^{m}(g, 0)\right] \\
& \quad
\end{aligned}
$$

for $j=R+1, \ldots, J$.

\subsection{Calibration Details}

\subsubsection{Stochastic Structure of Medical expenses}

When calibrating the five state Markov process of medical expense shocks, we allow one of the states to be associated with nursing home stays and allow the probabilities of a nursing home stay to vary with age. We estimate the transition probabilities in and out of this state using the following targets. The probabilities of entry into the nursing home state are chosen to match the distribution of age of first nursing home entry for individuals aged 65 and above. This distribution is taken from Murtaugh et al. (1997). They find that $21 \%$ of nursing home stayers have their first entry between ages $65-74,46 \%$ between ages 75-84, and $33 \%$ after age 85 . The probabilities of exiting the nursing home state are chosen to match 
the average years of nursing home stay over their lifetime organized by age of first entry. We limit attention to stays of at least 90 days because we want to focus on true long-term care expenses. Murtaugh et al. (1997) do not report the figures we need. However, we are able to impute these durations by combining data they provide with data from Liu et al. (1994). The specific targets are as follows. For those who had a first entry between 65-74, the average duration of all nursing home stays is 3.9 years. For those whose first entry is between the ages of 75-84 the average duration is 3.2 years and for those with first entry after age 85 the average duration is 2.9 years.

The above targets are all conditional on a nursing home entry. In order to estimate the unconditional probability of a nursing home entry, we target the probability that a 65 year old will enter a nursing home before death for a long term stay. That probability is 0.295 and is imputed using data from the two sources above.

In order to hit these targets, as well as the French and Jones (2004) AR(1) targets, we use a simulated method of moments procedure that does a bias correction for the well known downward bias in estimated $\mathrm{AR}(1)$ coefficients.

\subsubsection{Preferences}

We set $\beta=0.98$. Following the macro literature, we set $\sigma$, equal to $2.0 .^{26}$ The degree of joint consumption is governed by $\chi$. We set $\chi$ to 0.67 following Attansio, Low and Sanchez-Marcos (2008).

We set $\gamma$, the leisure exponent for females to 2. This is the baseline value used by Erosa, Fuster and Kambourov (2011). This choice in conjunction with steady-state hours worked implies a theoretical Frisch-elasticity of 2.43. This choice implies that the correlation between the year-on-year growth rate of the husbands wages and the corresponding growth rate of the wive's hours worked is -0.34 in our model. For purposes of comparison, the model of Heathcote et al. (2010) produces a correlation of -0.11 for the same statistic.

We allow the parameter $\psi(\mathbf{s})$ to vary with the education level of each household member. The targets, taken from McGrattan and Rogerson (2007), are average female hours by educational attainment of both household members. Expressed as a fraction of a total time endowment of 100 hours per week, they are 0.16 for high-school-educated households, 0.17 for households where the female has a high-school degree and her spouse has a college degree, 0.24 for households where the female has a college degree and her husband has a high-school degree, and 0.21 for college-educated households. The corresponding parameter values are $3.2,1.6,2.4$, and 2.1. For retired households, the value of $\psi^{R}$ is set to the weighted average of $\psi(\mathbf{s})$ for the working population.

\footnotetext{
${ }^{26}$ See for example Castañeda et al. (2003), Heathcote et al. (2010) and Storesletten et al. (2004).
} 
The parameter that governs the extent of disutility the household experiences if the female is participating in the labor market, $\phi(\mathbf{s})$, also varies with education. The targets for this parameter, taken from Kaygusuz (2010), are female participation rates by educational attainment of each household member. The participation rates are for married females aged 50 to 59. For high-school-educated households the rate is 0.48 . For households with highschool-educated females and college-educated males the rate is 0.45 . For households with college-educated females and high-school-educated males the rate is 0.68 and for collegeeducated households the rate is 0.58 . The corresponding parameter values we obtain are $0.33,0.22,0.16$, and 0.15 .

\subsubsection{Technology}

Consumption goods are produced according to a production function,

$$
F(K, L)=A K^{\alpha} L^{1-\alpha}
$$

where capital depreciates at rate $\delta$. The parameters $\alpha$ and $\delta$ are set using their direct counterparts in the U.S data: a capital income share of 0.3 and an annual depreciation rate of $7 \%$ (Gomme and Rupert (2007)). The parameter $A$ is set such that the wage per efficiency unit of labor is normalized to one under the baseline calibration.

\subsubsection{Earnings Process}

The basic strategy for calibrating the labor productivity process follows Heathcote, Storesletten, and Violante (2010) who also consider earnings for married households. We assume that college graduates begin their working career four years later than high school graduates. The specific form of the labor productivity process is:

$$
\log \Omega^{i}\left(j, \epsilon_{e}, s^{i}\right)=\alpha_{1} \mathbf{I}\left(s^{i}=c o l\right)+\alpha_{2} \mathbf{I}(i=f)+\beta_{1} j+\beta_{2} j^{2}+\beta_{3} j^{3}+\epsilon_{e}^{i},
$$

where $\alpha_{1}$ and $\alpha_{2}$ are intercepts that capture the college premium and the gender gap. The $\beta$ 's determine the experience premium. The specific values of these parameters are $\alpha=$ $4.96 \times 10^{-1}, \alpha_{2}=-4.78 \times 10^{-1}, \beta_{1}=4.80 \times 10^{-2}, \beta_{2}=-8.06 \times 10^{-4}$ and $\beta_{3}=-6.46 \times 10^{-7}$. All these values are taken from Heathcote et al. (2010).

Following Heathcote et al. ( 2010), we assume that females and males face a persistent productivity shock process. In particular, $\epsilon_{e}^{i}$ is assumed to follow an $\mathrm{AR}(1)$ process with a serial correlation coefficient of $\epsilon_{e}^{i}=0.973$ and a standard deviation of 0.01 . We allow the innovation to earning productivity to be correlated with the spouse's innovation. Heathcote 
et al. (2010) choose this correlation to reproduce a targeted correlation of male wage growth and female wage growth of 0.15 . We set the correlation of the earnings innovations to match this same target. The resulting correlation between the two earnings innovations is 0.05.

Heathcote et al. (2010) also allow for a transient shock to labor productivity. We abstract from this second shock. This reduces the size of the state space for working households and allows us to model the problem of retirees in more detail.

The distribution of initial productivity levels $\Gamma_{e}$ is assumed to be bivariate normal with a standard deviation of 0.352 , a correlation of 0.517 and a gender productivity gap of 0.62 in 1970. All of these targets are taken from Heathcote et al. (2010) and apply to males and females. ${ }^{27}$

One difference between us and Heathcote et al. (2010) is that we allow for an earnings state that has a much lower level of earnings as compared to what Gaussian quadrature methods would imply. This is done to deal with the fact that some households receive very little social security income during their retirement. The resulting process is non-Gaussian. In order to recover to make this process consistent with the estimates of Heathcote et al. (2010), we use the same simulated method of moments strategy described above for the medical expense process.

\subsubsection{Progressive Income Tax Formula}

The effective progressive income tax formula is given by:

$$
\tau^{y}\left(y^{d i s p}, d\right)=\left[\eta_{1}^{d}+\eta_{2}^{d} \log \left(\frac{y^{d i s p}}{\bar{y}}\right)\right] y^{d i s p}
$$

where $y^{\text {disp }}$ is disposable household income, $\bar{y}$ is mean income in the economy. Guner et al. (2012) estimate $\eta_{1}^{0}=0.113$ and $\eta_{2}^{0}=0.073$ for married households and $\eta_{1}^{d \in\{1,2\}}=0.153$ and $\eta_{2}^{d \in\{1,2\}}=0.057$ for single households.

The U.S. Federal tax code allows tax-filers a deduction for medical expenses that exceed $7.5 \%$ of income. Our income tax schedules indirectly account for deductions when estimating effective tax functions. However, their effective tax functions are averages across many households and do not capture the full benefit of this deduction to those who experience large medical expenditure shocks such as long-term care. We allow for a deduction for medical expenses that exceed $7.5 \%$ of income.

U.S. Federal tax code provides for an exemption of SS benefits. This exemption is phased out in two stages as income rises. Table 16 reports exemption thresholds and minimum

\footnotetext{
${ }^{27}$ Specifications similar to this have been used by Attansio et al. (2008) and Heathcote et al. (2008) to model the joint earnings of married couples.
} 
Table 16: Exemption thresholds and minimum income levels for taxation of social security benefit income

\begin{tabular}{lcc}
\hline \hline Description & Levels $(\$)$ & \% of ave. earnings \\
\hline Threshold 1 & & \\
$\quad$ Single $\left(T_{s}^{1}\right)$ & 25,000 & 53 \\
Married $\left(T_{m}^{1}\right)$ & 32,000 & 67 \\
Threshold 2 & & \\
Single $\left(T_{s}^{2}\right)$ & 34,000 & 72 \\
Married $\left(T_{m}^{2}\right)$ & 44,000 & 93 \\
Minimum income & & \\
single $\left(\underline{Y}_{s}\right)$ & 4,500 & 9 \\
married $\left(\underline{Y}_{m}\right)$ & 6,000 & 13 \\
\hline \hline
\end{tabular}

Source: Scott, C. and J. Mulvey (2010). "Social Security: Calculation and History of Taxing Benefits", Congressional Research Service.

income levels by marital status. The left column of Table 16 reports the actual dollar amounts in the year 2000. The right column expresses these figures as a fraction of average earnings of full-time, prime-age male workers in 2000 which according to SSA was $\$ 47,552.16$. According to our source, the thresholds and minimum income are not indexed to inflation or wage growth.

We use these thresholds to compute the exemptions formulas in the following way. We start by calculating provisional income, $Y$, which is defined as asset income, $Y^{a}$, plus half of the household's SS income, $Y^{s s}$. If $Y<T_{i}^{1}, i \in\{s, m\}$, there is a full exemption for SS benefits and taxable income for that household is equal to $Y^{a}$ net of the medical expense tax deduction. If $T_{i}^{1}<Y<T_{i}^{2}, i \in\{s, m\}$, taxable income is given by

$$
Y^{a}+0.5 \min \left(Y^{s s}, Y-T_{i}^{1}\right)
$$

net of the medical expense tax deduction if eligible. If $Y>T_{i}^{2}, i \in\{s, m\}$, then taxable income is given by

$$
Y^{a}+\min \left\{0.85 Y^{s s}, 0.85\left[Y-T_{i}^{2}+\min \left(\underline{Y}_{i}, 0.5 Y_{i}^{s s}\right)\right]\right\},
$$

net of medical expense tax deduction if eligible. 


\subsubsection{Social Security Benefits}

The U.S. Social Security system links a worker's benefits to an index of the worker's average earnings, $\underline{e}$. Benefits are adjusted to reflect the annual cap on contributions and there is also some progressivity built into the U.S. Social Security system. We use the following formula to link contributions to benefits for an individual

$$
\hat{S}(\bar{e})= \begin{cases}s_{1} \bar{e}, & \text { for } \bar{e} \leq \tau_{1}, \\ s_{1} \tau_{1}+s_{2}\left(\bar{e}-\tau_{1}\right), & \text { for } \tau_{1} \leq \bar{e} \leq \tau_{2}, \\ s_{1} \tau_{1}+s_{2}\left(\tau_{2}-\tau_{1}\right)+s_{3}\left(\bar{e}-\tau_{2}\right), & \text { for } \tau_{2} \leq \bar{e} \leq \tau_{3}, \\ s_{1} \tau_{1}+s_{2}\left(\tau_{2}-\tau_{1}\right)+s_{3}\left(\tau_{3}-\tau_{2}\right), & \text { for } \bar{e} \geq \tau_{3} .\end{cases}
$$

Following the Social Security administration, we set the marginal replacement rates, $s_{1}, s_{2}$, and $s_{3}$ to $0.90,0.33$, and 0.15 , respectively. The threshold levels, $\tau_{1}, \tau_{2}$, and $\tau_{3}$, are set to $20 \%, 125 \%$ and $246 \%$ of average earnings for all workers. The U.S. Social Security system also provides spousal and survivor benefits. We model these benefits. Household benefits are determined using the following formula

$$
S(\overline{\mathbf{e}}, d)= \begin{cases}\hat{S}\left(\max _{i \in\{m, f\}}\left\{\bar{e}^{i}\right\}\right)+\max \left\{0.5 \hat{S}\left(\max _{i \in\{m, f\}}\left\{\bar{e}^{i}\right\}\right), \hat{S}\left(\min _{i \in\{m, f\}}\left\{\bar{e}^{i}\right\}\right)\right\}, & \text { if } d=0, \\ \max \left\{\hat{S}\left(\bar{e}^{m}\right), \hat{S}\left(\bar{e}^{f}\right)\right\} . & \text { if } d \in\{1,2\} .\end{cases}
$$




\section{References}

[1] Attanasio A., H. Low and V. Sanchez-Marcos, (2008). "Explaining Changes in Female Labor Supply in a Life-Cycle Model," American Economic Review, Vol. 98 no. 4, pp: $1517-52$.

[2] Auerbach, A. and L.J. Kotlikoff, (1987) Dynamic Fiscal Policy Cambridge University Press.

[3] Brown, J. and A. Finkelstein (2008). "The Interaction of Public and Private Insurance: Medicaid and the Long-Term Care Insurance Market." American Economic Review, vol. 98, no. 3, pp: 1083-1102.

[4] Castañeda, A., J. Diaz-Gimenez, J.V. Ríos-Rull (2003). "Accounting for the U.S. Earnings and Wealth Inequality," Journal of Political Economy, vol. 111, no. 4, pp: 818-857.

[5] Cohen, W. J. and M. Friedman (1972). "Social Security: Universal or Selective." American Enterprise Institute for Public Policy Research.

[6] Conesa J. C., and D. Krueger (1999). "Social Security Reform with Heterogeneous Agents." Review of Economic Dynamics, Vol. 2, no. 4, pp: 757-795.

[7] De Nardi, M., E. French, J. B. Jones (2010). "Why Do the Elderly Save? The Role of Medical Expenses," Journal of Political Economy, Vol. 118, no. 1, pp: 39-75.

[8] De Nardi, M., E. French, J. B. Jones (2012). "Medicaid insurance in old age," Working Paper WP-2012-13, Federal Reserve Bank of Chicago.

[9] Erosa, A., L. Fuster and G. Kambourov (2012). "Labor supply and government programs: A cross-country analysis," Journal of Monetary Economics, Vol. 59 no. 1, pp: 84-107.

[10] Feenberg, D. and J. Skinner, (1994) "The Risk and Duration of Catastrophic Health Care Expenditures." The Review of Economics and Statistics vol. 76, no. 4, pp: 633647.

[11] Feldstein, M. (1987). "Should Social Security Be Means Tested?" Journal of Political Economy, vol. 95, no. 3. pp: 468-484.

[12] French, E., and J. B. Jones (2004). "On the Distribution and Dynamics of Health Care Costs," Journal of Applied Econometrics, vol. 19, no. 4, pp: 705-721.

[13] Fuster, L., A. Imrohoroglu and S. Imrohoroglu (2007). "Elimination of Social Security in a Dynastic Framework," forthcoming, Review of Economic Studies, vol. 74, no. 1, pp: $113-145$.

[14] Golosov, M. and A. Tsyvinski, (2006) "Designing Optimal Disability Insurance: A Case for Asset Testing." Journal of Political Economy vol. 114, no. 2, pp: 257-279. 
[15] Gomme, P. and P. Rupert (2007). "Theory, Measurement and Calibration of Macroeconomic Models," Journal of Monetary Economics, vol. 54, no. 2, pp: 460-497.

[16] Guner, N., R. Kaygusuz and G. Ventura (2012) "Taxing Women: A Macroeconomic Analysis." Journal of Monetary Economics, vol. 59, no. 5, pp: 111-128.

[17] Heathcote J., K. Storesletten and G. L. Violante (2010). "The Macroeconomic Implications of Rising Wage Inequality in the United States," Journal of Political Economy, Vol. 118 no. 4, pp: 681-722.

[18] Hong, J. H. an J-V. Ríos-Rull (2007). "Social security, life insurance and annuities for families," Journal of Monetary Economics, Vol. 54, no. 1, pp: 118-140.

[19] Hoover, D.R., S. Crystal, R. Kumar, U. Sambamoorthi and J.C. Cantor (2002) "Medical Expenditures during the Last Year of Life: Findings from the 1992-1996 Medicare Current Beneficiary Survey," Health Services Research, Vol. 37 no. 6 pp: 1625-1642.

[20] Hubbard, G.R., J. Skinner, and S. Zeldes (1995). "Precautionary Savings and Social Insurance," Journal of Political Economy, vol. 103, no. 2, pp: 360-399.

[21] Keane, M. and R. Rogerson (2012). "Micro and Macro Labor Supply Elasticities: A Reassessment of Conventional Wisdom," Journal of Economic Literature Vol 50 no. 2, pp: $464-76$.

[22] Kopecky, K. and T. Koreshkova (2007). "The Impact of Medical and Nursing Home Expenses and Social Insurance Policies on Savings and Inequality," unpublished manuscript.

[23] Kaygusuz, R. (2010). "Taxes and Female Labor Supply," Review of Economic Dynamics, Vol. 13, no. 4, pp: 725-741.

[24] Liu, K. T. McBride and T. Coughlin (1994) "Risk of Entering Nursing Homes for Long versus Short Stays," Medical Care, Vol 32, no. 4 pp: 315-327.

[25] McGrattan E. R. and R. Rogerson (2007). "Changes in the distribution of family hours worked since 1950," Staff Report 397, Federal Reserve Bank of Minneapolis.

[26] McGrattan E. R. and E. C. Prescott (2012) "On Financing Retirement with an Aging Population." Staff Report 472, Federal Reserve Bank of Minneapolis

[27] Murtaugh, C. M., P. Kemper, B.C. Spillman and B. Lepidus Carlson (1997) "The Amount, Distribution, and Timing of Lifetime Nursing Home Use," Medical Care, Vol. 35 no. 3, pp: 204-218.

[28] Nishiyama, S. and K. Smetters (2007). "Does Social Security Privatization Produce Efficiency Gains?" The Quarterly Journal of Economics, vol. 122, no. 4, pp: 16771719. 
[29] Poterba, J.M., S. F. Venti and D. A. Wise, (2011). "Family Status Transitions, Latent Health, and the Post-Retirement Evolution of Assets," in ed. D. Wise, "Explorations in the Economics of Aging," University of Chicago Press.

[30] Sefton, J., J. van de Ven and M. Weale, (2008) "Means Testing Retirement Benefits: Fostering Equity or Discouraging Savings?" The Economic Journal vol. 118, pp: 556590.

[31] Storesletten, K., C. Telmer, and A. Yaron (2004). "Consumption and Risk Sharing Over the Life Cycle," Journal of Monetary Economics, vol. 51, pp: 609-633.

[32] Tran, C. and A. Woodland (2012). "Trade-Offs in Means Tested Pension Design," Unpublished Manuscript. 